\title{
Synthesis, assembly and degradation of thylakoid membrane proteins
}

\author{
Yves Choquet, Olivier Vallon* \\ CNRS/UPR1261, Institut de Biologie Physico-Chimique, 13, rue Pierre-et-Marie-Curie, 75005 Paris, France
}

(Received 15 March 2000; accepted 17 April 2000)

\begin{abstract}
The thylakoid membrane of chloroplasts contains four major protein complexes, involved in the photosynthetic electron transfer chain and in ATP synthesis. These complexes are built from a large number of polypeptide subunits encoded either in the nuclear or in the plastid genome. In this review, we are considering the mechanism that couples assembly (association of the polypeptides with each other and with their cofactors) with the upstream and downstream steps of the biogenetic pathway, translation and proteolytic degradation. We present the contrasting images of assembly that have emerged from a variety of approaches (studies of photosynthesis mutants, developmental studies and direct biochemical analysis of the kinetics of assembly). We develop the concept of control by epistasy of synthesis, through which the translation of certain subunits is controlled by the state of assembly of the complex and address the question of its mechanisms. We describe additional factors that assist in the integration and assembly of thylakoid membrane proteins. (C) 2000 Société française de biochimie et biologie moléculaire / Éditions scientifiques et médicales Elsevier SAS
\end{abstract}

thylakoid membrane / chloroplast / photosynthesis / membrane protein assembly / translation / proteolysis

\section{Introduction}

The light reactions of oxygenic photosynthesis are carried out by four large enzymatic complexes located in the thylakoid membrane (figure 1). All of them are oligomeric proteins, made of between 7 and more than 20 polypeptides, and they bind a variety of cofactors and pigments in a well-defined structural arrangement. In recent years, our understanding of the system has received tremendous benefit from the two most rapidly expanding fields of biology: genomics and 3D-structure analysis. A number of chloroplast genomes have been fully sequenced, as well as the complete genome of the cyanobacterium Synechocystis sp. PCC6803, while the sequence of the Arabidopsis nuclear genome will soon be completed. With the help of reverse genetics, this will put in our hands the complete set of polypeptides from which this complex system is built up (structural genes, regulators and assembly catalysts). The 3D-structures of photosystem I (PSI) and light harvesting complex II will soon reach atomic resolution, while those of the other complexes, the photosystem II (PSII) reaction center, cytochrome $b_{6} f$ and the $\mathrm{H}^{+}$-ATP synthase, either are underway or can be largely inferred from those of their bacterial or mitochondrial homologues.

Still, one of the most fascinating aspects of this system remains poorly understood. We largely ignore how the

\footnotetext{
* Correspondence and reprints: vallon@ibpc.fr Abbreviations: CES, control by epistasy of synthesis; LHCP, light harvesting chlorophyll $a / b$ protein; PSI, photosystem I; PSII, photosystem II; SRP, signal recognition particle
}

interactions that bind these polypeptides together are established and destroyed throughout the biogenesis of the membrane. This is an arduous question not only because of the large number of polypeptides involved, but also because of their dual genetic origin. Within a same complex, subunits encoded by the chloroplast genome are associated in a defined stoichiometry with subunits that are encoded by the nuclear genome, translated on cytosolic ribosomes and imported into the chloroplast. Thus, specific mechanisms should operate to allow the stoichiometric accumulation of the various subunits encoded by the two genetic compartments in the amount required for their assembly. At the level of translation, some degree of coordination appears necessary, not only to avoid wasteful production of subunits in excess of their assembly partners, but also because some of these polypeptides bind chlorophyll, whose triplet state would lead to the formation of deleterious singlet oxygen when photochemistry is defective. The two genetic compartments, which use widely different systems for producing proteins, must exchange specific signals to coordinate gene expression. In the chloroplast, polycistronic transcription units may combine genes for different complexes and may be trimmed to monocistronic mRNAs. Consequently, the level of expression of each protein has to be regulated individually. As described elsewhere in this issue (Barkan and Goldschmidt-Clermont, Monde et al., Zerges), a large part of the control of chloroplast gene expression has moved to the post-transcriptional level, with numerous nucleus-encoded factors governing mRNA processing, stability and translation for a specific chloroplast gene product. 


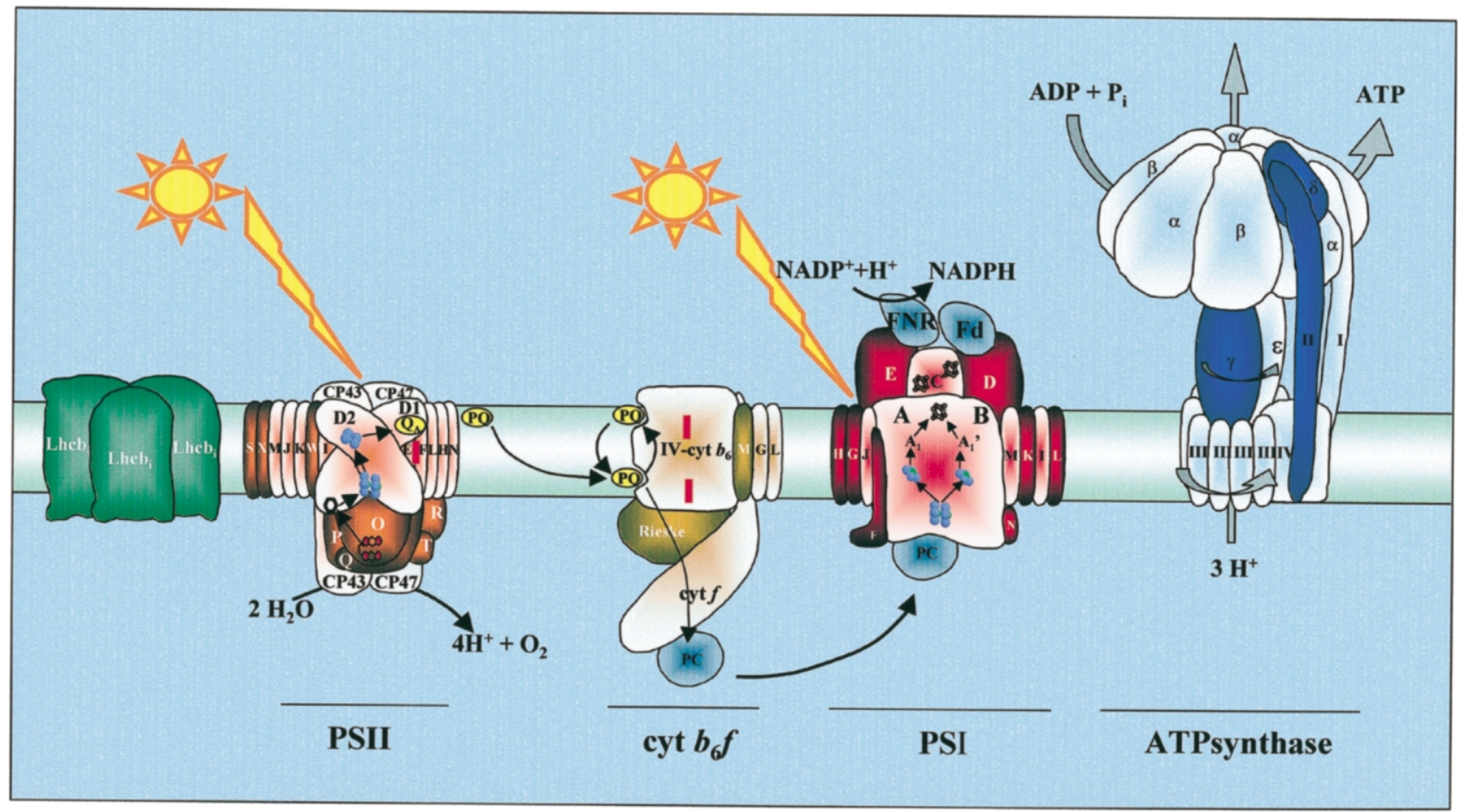

Figure 1. Supramolecular organization of the thylakoid membrane. Chloroplast-encoded subunits are indicated in light colors and nucleus-encoded subunits in dark colors. Each subunit is indicated by is common name, or by the letter of the gene ( $p s b$, pet, $p s a$ ) that encodes it. Light harvested by the photosystems I and II (PSI, PSII) and their associated light harvesting complexes (LHCI, LHCII) triggers oxidation of a photochemical chlorophyll $a$ dimer (P680, P700, respectively). In PSII, P680 ${ }^{+}$is reduced by electrons abstracted from water through a Mn cluster and a reactive tyrosine $\mathrm{Y}_{\mathrm{Z}}$. On the acceptor side, the intra-protein electron transfer chain comprises a pheophytin, a non-heme iron and a tightly bound quinone $\mathrm{Q}_{\mathrm{A}}$. At the $\mathrm{Q}_{\mathrm{B}}$ site, plastoquinone (PQ) is reduced to plastoquinol, which will be oxidized at the $\mathrm{Q}_{\mathrm{o}}$ site of cytochrome $b_{6} f$. One electron travels through the Rieske protein and cytochrome $f$ to the soluble electron carrier plastocyanin (PC). The other electron, via cytochrome $b_{6}$ hemes, reduces another PQ at the $\mathrm{Q}_{\mathrm{i}}$ site, resulting in $\mathrm{H}^{+}$pumping by the so-called Q-cycle. On the lumenal face of PSI, PC reduces oxidized P700. Two parallel electron transfer chains in PSI converge towards $F_{X}$, a cluster at the interface of PsaA and PsaB. After reducing the $F_{A}$ and $F_{B}$ clusters and ferredoxine $(\mathrm{Fd})$, the electron is used by ferredoxine-NADP ${ }^{+}$-reductase $(\mathrm{FNR})$ to generate NADPH. Operation of the electron transfer chain generates a $\Delta \mu \mathrm{H}^{+}$which is used by the $\mathrm{CF}_{0}-\mathrm{CF}_{1}$ ATP synthase to generate ATP.

Photosynthesis research has now put in our hands a large panel of genetic, biochemical and biophysical tools, with which we can address this important issue in a systematical manner, with the hope to shed some light on the general principle that governs assembly of complex membrane proteins. The biogenesis of thylakoid membrane proteins has recently been reviewed in detail [1]. In the present paper, we will concentrate on the mechanisms that couple the assembly process to two essential moments of the life of a polypeptide, translation and proteolysis.

\section{Cytochrome $b_{\sigma} f:$ a case study.}

In this section we will describe the assembly of the cytochrome $b_{6} f$ complex, to serve as an illustration of the common themes encountered in the study of the other thylakoid membrane proteins.

Cytochrome $b_{6} f$ is the simplest complex of the thylakoid membrane in terms of polypeptide composition. It catalyses the reduction of plastocyanin at the expense of reduced plastoquinol and contributes to the formation of the proton gradient used to synthesize ATP. It is structurally and functionally homologous to the cytochrome $b c_{1}$ complex found in mitochondria and bacteria, whose structure has been determined by X-ray crystallography $[2,3]$. The isolated complex $[4,5]$ contains four major subunits: cytochrome $f$ binds one $c$-type heme, cytochrome $b_{6}$ carries two $b$-type hemes, subunit IV is devoid of prosthetic groups but contributes to the formation of the quinol binding site, and the Rieske protein binds the [2Fe-2S] cluster. The first three subunits are encoded by 
the chloroplast genes petA, petB and petD, while the Rieske protein is encoded by the nuclear gene PETC, translated on cytoplasmic ribosomes and imported into the chloroplast. The complex contains also several small polypeptides $\left(M_{\mathrm{r}} \approx 4 \mathrm{kDa}\right)$ with a single transmembrane helix, which have no counterpart in cytochrome $b c_{1}$ complex and do not appear to bind cofactors: PetG and PetL are chloroplast encoded [6, 7], while PetM is the product of a nuclear gene [8]. In addition, the product of the chloroplast $y c f 6$ gene, was recently reported to be required for the accumulation of the cytochrome $b_{6} f$ complex and present in the isolated complex [9]. While the other subunits are present as one copy per complex [5], the stoeichiometry of Ycf6 has not been established so far.

All the subunits of the complex are intrinsic polypeptides. For the majority of them, most of the polypeptide chain is deeply embedded in the thylakoid membrane. However, cytochrome $f$ and the Rieske protein are anchored in the membrane by a single transmembrane helix with the large cofactor binding domain in the thylakoid lumen. Cytochrome $b_{f} f$ in its active enzymatic form is a dimer, but can be irreversibly converted to an inactive monomeric form if lipids are omitted during the preparation, or if the concentration of detergent is increased [10]. The Rieske protein is lost during monomerization and can be extracted from the membrane by chaotrops, so that it appears more loosely associated than the other proteins $[10,11]$. Upon more drastic conditions, the monomeric complex further looses PetL, as well as its chlorophyll component. Hence, it is possible to remove some of the subunits in vitro without totally compromising the stability of the complex. As will be shown below, genetic studies indicate that assembly in vivo also is not an all-or-none process.

A number of mutations impairing accumulation of the cytochrome $b_{\sigma} f$ complex have been isolated from a wide range of organisms, from the green alga Chlamydomonas reinhardtii to higher plants [12-14]. As is the rule in the genetic analysis of photosynthesis, several types of mutations can be obtained by functional screening. Some lie in the structural genes (chloroplastic or nuclear) encoding the subunits of the complex, while others affect nuclear genes that control the expression of chloroplast genes at a post transcriptional level [12, 15-17].

Another category of mutations affects the machinery required for the fixation of hemes to the apocytochromes (see Nakamoto et al., this issue), a strict requirement for the stabilization of cytochromes and further assembly. In contrast, assembly of the [2Fe-2S] cluster on the Rieske protein is a spontaneous process in vitro [18]. This does not necessarily preclude the need for additional factors in vivo. Remember that heme binding to cytochrome $b_{6}$, a spontaneous reaction in vitro [19], requires in vivo the products of at least four nuclear genes $C C B 1-C C B 4$ in Chlamydomonas [20]. An enigmatic chlorophyll $a$ is bound to cytochrome $b_{6} f$, probably together with a caro- tenoid [21, 22]. Although this chlorophyll does not appear to be involved in electron transport, it may be required for assembly. A chlN mutant of Chlamydomonas, unable to synthesize chlorophyll in the dark, was found to lack cytochrome $b_{6} f$ [21]. However, cytochrome $b_{6} f$ is present in low amounts in etioplasts $[6,23]$ which lack chlorophyll, so that the generality of this requirement remains uncertain.

In recent years, a systematic analysis of site-directed mutants in the chloroplast pet genes has set the rules for assembly of the complex. Most mutations, although affecting primarily the expression of a single subunit, result in a pleiotropic decrease of the accumulation of the other subunits as well $[12,24,25]$. For example, deletions of either petA, petB, petD [24, 25], petG [26] or ycf6 [9] from the chloroplast genome result in a dramatic decrease, by a factor of ten or more, of the accumulation of the remaining subunits. These results point towards a concerted accumulation of the various polypeptides of the complex, whereby interaction of a subunit with all its assembly partners in the membrane is necessary for its stable accumulation. There are two notable exceptions to this rule. In Chlamydomonas, deletion of the pet $L$ gene still allows the accumulation (in exponentially growing cells only) of $25 \%$ of the other subunits, assembled in a functional complex [7]. This partial complex is less stable than the wild type one, as it is converted to a monomer and looses specifically the Rieske protein during isolation. The latter two effects are not necessarily coupled, since a petB mutant altered in the $\mathrm{Q}_{\mathrm{o}}$ site lost the Rieske protein but retained the dimeric structure and PetL [27]. Similarly, in strains lacking the Rieske protein, a partial complex resulting from the assembly of the remaining subunits (including PetL) is accumulated to about $50 \%$ of the wild type level $[12,28]$. This complex, due to the lack of the [2Fe-2S] cluster, is not functional, but retains the dimeric structure. In the cytochrome $b c_{1}$ complex, the Rieske protein is even more clearly dispensable for assembly, since Rieske protein-less mutants of Rhodobacter capsulatus assemble a stable sub-complex, onto which the purified protein can be reconstituted in vitro [29]. In contrast, in the aquatic angiosperm Lemna, a mutant devoid of the Rieske protein mRNA did not accumulate the other subunits of cytochrome $b_{6} f$ [13].

In Chlamydomonas, both the PetL- and Rieske proteinless complexes are lost when the culture enters stationary phase. For the Rieske protein mutants, this degradation appears to be carried out by a Clp protease (for a description of chloroplast proteases, see Adam, this issue), since attenuation of the $c l p P$ gene results in a marked stabilization of the Rieske-less complex in the mutant [30]. Interestingly, the mutant Rieske protein itself is stabilized by attenuation of $\operatorname{clp} P$, which suggests that it is also a substrate for the protease. In another study, the unassembled Rieske protein associated with the mem- 
brane during in organello import appeared to be degraded by the FtsH protease [31].

Two types of mechanisms appear responsible for the concerted accumulation of cytochrome $b_{6} f$ subunits: degradation of unassembled polypeptides, and regulation of translation by assembly. Both mechanisms have been studied in detail in Chlamydomonas, by pulse chase experiments performed on strains deleted for one of the pet genes. These experiments showed that the half life of subunit IV and cytochrome $b_{6}$, but not their initial synthesis rate, was highly decreased upon deletion of another subunit of the complex. For example the half life of subunit IV drops from almost $2 \mathrm{~h}$ in the wild type to $45 \mathrm{~min}$ and $15 \mathrm{~min}$ in strains lacking cytochrome $f$ or cytochrome $b_{6}$, respectively [24]. This indicates that the unassembled subunit IV is rapidly degraded when it cannot assemble, i.e., that assembly converts it from a highly unstable form to a form that is no longer susceptible to proteolytic attack. This could be brought about simply by shielding those motifs that can be recognized by proteases. The protease(s) responsible for this type of degradation have not been identified yet. ClpP does not seem to be involved, since attenuation of the gene did not lead to enhanced accumulation of the fully unassembled subunits in this type of mutants [30].

The behavior of cytochrome $f$ appears completely different from that of the other subunits. In the absence of its assembly partners, cytochrome $b_{6}$ or subunit IV, its synthesis rate drops to about $10 \%$ of that observed in the wild type [24]. Cytochrome $f$ synthesized in those conditions is inserted in the membrane and is as stable as in the wild type, even though it is not assembled. Thus, there is a hierarchical organization of the expression of the cytochrome $b_{6} f$ subunits, which has been described as a control by epistasy of synthesis (CES) [32, 33]. Cytochrome $b_{6}$ and subunit IV are dominant over cytochrome $f$, whereas cytochrome $f$, which requires the presence of its dominant assembly partners to be synthesized at wild type rate, is called a CES protein.

At the molecular level, this assembly-mediated control of cytochrome $f$ translation is an autoregulation of translation. The signal responsible for this regulation is carried by the C-terminal domain of the cytochrome $f$, i.e., the transmembrane helix and the 15 amino acids stromal extension. Indeed, strains lacking accumulation of this C-terminal domain (either because the whole cytochrome $f$ is unstable and fails to accumulate, or because this region was specifically deleted or mutated) escape autoregulation: they show a three-fold oversynthesis of cytochrome $f$, whether the dominant subunits are synthesized or not $[33,34]$. Thus, cytochrome $f$ synthesis is already repressed to some extent in wild type, in order to adjust the production of cytochrome $f$ to the synthesis rate of the other subunits. Site directed mutagenesis experiments on the C-terminal domain of cytochrome $f$ have narrowed down the regulatory motif to an eight amino acid stretch located immediately after the end of the transmembrane helix (Choquet and Wollman, unpublished).

\subsection{Membrane-KKKQFEKV}

Mutations at positions 2, 3, 6 and 7 did not affect autoregulation, but a Lys to Met substitution at position 1 or a Phe to Ser substitution at position 5 yielded a completely unregulated cytochrome $f$, with a three-fold increased translation rate. The importance of the other residues, as well of the possible implication of residues from the transmembrane helix, is under study.

The target for this autoregulation resides within the petA 5'UTR, which governs translation initiation. Strains where cytochrome $f$ is translated under the control of another unrelated 5'UTR no longer exhibit the assemblydependent control of cytochrome $f$ synthesis. Furthermore, the petA mRNA 5'UTR is able per se to confer the CES behavior to a reporter gene translated under its control [33]. It was proposed that the regulatory motif carried by unassembled cytochrome $f$ is able to interact directly or indirectly with the 5'UTR of the petA mRNA. Upon assembly, it would be shielded by the other subunits or undergo a conformational change impairing this interaction. As this motif seems too short to promote a sequence specific protein-RNA interaction, the interaction is likely indirect and should therefore rely on a ternary effector. This factor would be trapped by the regulatory motif of unassembled cytochrome $f$; it would be released upon assembly and become available for translation, as illustrated in figure 2. A possible candidate is the nucleusencoded TCA1 factor, the only factor identified to date that is required for the translation initiation of the petA mRNA [35] (Wostrikoff et al., unpublished observations.). However, the participation of TCA1 in the CES process still awaits demonstration.

Whether the epistatic control of cytochrome $f$ synthesis also operates in the chloroplast of higher plants remains to be elucidated. Tobacco mutants with a deletion in petD or pet $B$ failed to accumulate the complex [25], but synthesis of cytochrome $f$ has not been measured directly. The observed reduction in the size of petA-associated polysomes is difficult to interpret, since the tobacco petA is associated with other reading frames in a complex transcription unit. The crpl mutant of maize lacks translatable petD messenger due to a failure to process the petD mRNA. Interestingly, this mutant also shows a reduced synthesis of cytochrome $f$ [17]. But a close examination of the phenotype of the mutant and of the sequence of the cloned crpl gene led the authors to conclude that the decreased cytochrome $f$ synthesis was a primary effect of the mutation rather than an epistatic consequence of the decreased accumulation of subunit IV [36].

Together, the data presented above suggest a pathway, largely hypothetical, for the assembly of the cytochrome $b_{6} f$ complex. Genetic data point to an early interaction 


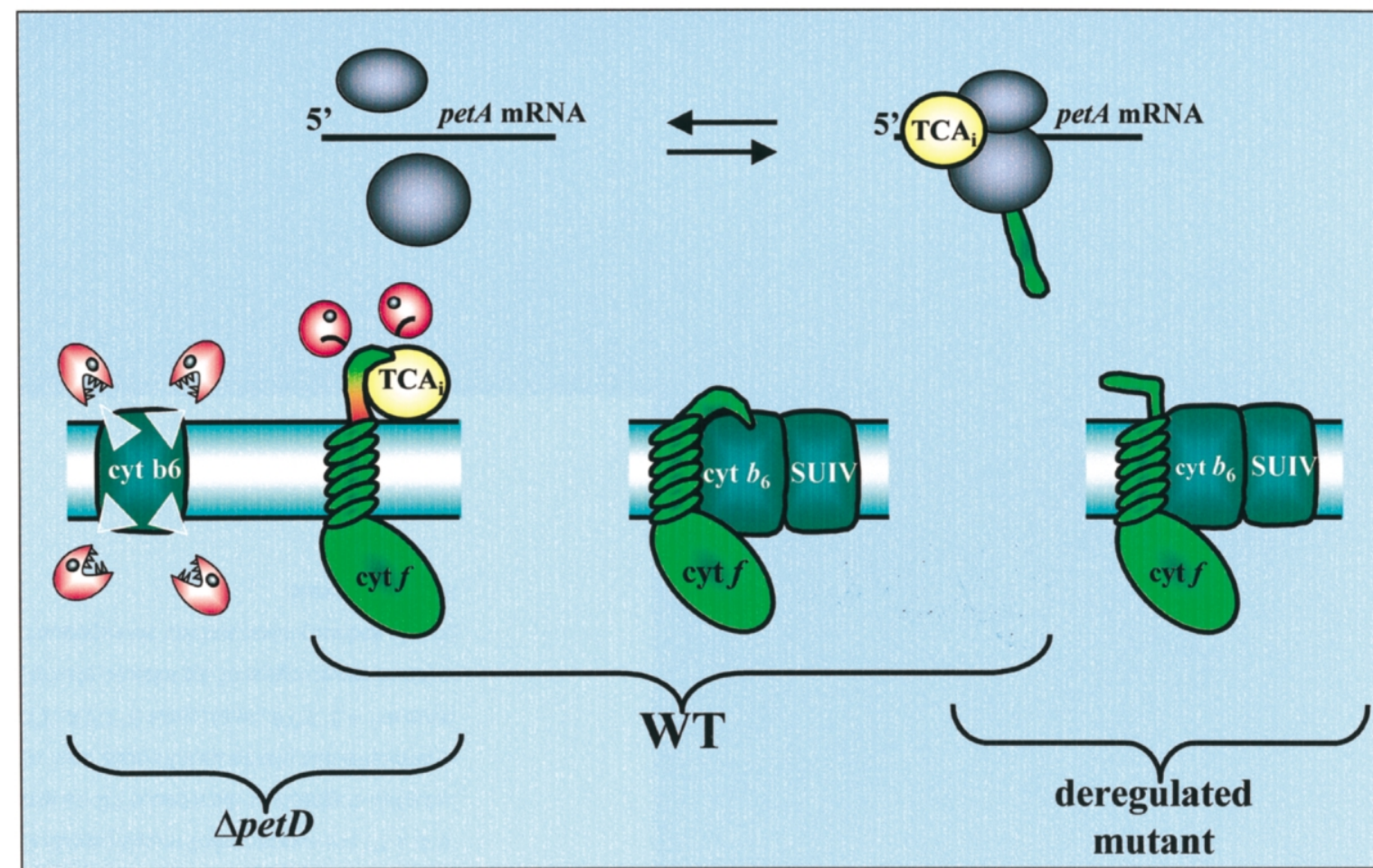

Accumulation of regulatory motif

Cyt. $f$ translation rate (\% of WT) maximal

$\sim 10 \%$ intermediate

$100 \%$ null

$\sim 300 \%$

Figure 2. Hypothetical description of cytochrome $f$ expression in wild type and mutant strains. The left part of the figure shows inhibition of cytochrome $f$ synthesis due to the accumulation of unassembled cytochrome $f$, as observed in strains lacking the dominant subunit IV. The dominant cytochrome $b_{6}$ is rapidly degraded. The putative TCA effector, trapped by the regulatory motif, is not available for translation initiation. The right part of the figure shows activation of cytochrome $f$ synthesis, in mutants where the regulatory motif has been destroyed by site-directed mutagenesis. $\mathrm{TCA}_{\mathrm{i}}$ can not bind anymore the motif and is totally available to activate translation. The intermediate rate of synthesis observed in wild-type cells (middle) results from an equilibrium between the left and right situations, $\mathrm{TCA}_{\mathrm{i}}$ being released upon assembly.

between subunit IV and cytochrome $b_{6}$ : the half life of subunit IV is shorter in the absence of cytochrome $b_{6}$ $(15 \mathrm{~min})$ than in the absence of cytochrome $f(45 \mathrm{~min})$ [24]. An early interaction between these two subunits is likely since cytochrome $b_{6}$ and subunit IV are homologous to the $\mathrm{N}$ - and $\mathrm{C}$-terminal parts, respectively, of the single cytochrome $b$ polypeptide of cytochrome $b c_{1}$. This interaction is probably driven by helix-helix recognition, reminiscent of those responsible for the folding of cytochrome $b$ in mitochondria or bacteria. It has been recently shown that the splitting of cytochrome $b$ into two nonoverlapping fragments that mimics cytochrome $b_{6}$ and subunit IV does not prevent its proper folding and assembly into a functional complex [37, 38]. At a later stage, this hypothetical subcomplex would interact with cytochrome $f$ and with the small subunits PetG and PetM. Cytochrome $f$, present in slight excess in the thylakoid membrane [5] is available for an early interaction with this $b_{6} / \mathrm{IV}$ subcomplex and may kinetically favor assembly with respect to the competing degradation process. Association with PetL and with the Rieske protein are probably late events in the assembly, since a partially stable complex is accumulated in the absence of these polypeptides. It would stabilize the dimeric form of the complex.

As a whole, the assembly of cytochrome $b_{6} f$ complex appears to integrate several key features that, as will be seen in the following sections, are common, with small variations, to the other protein complexes of the thylakoid membrane: i) a stabilization of the apoproteins upon fixation of their cofactor complement as a prerequisite for 
assembly; ii) a concerted accumulation of the subunit of the complex resulting from: 1) a rapid proteolytic degradation of most unassembled subunits; and 2) an assemblycontrolled regulation of the synthesis of one subunit; and iii) a sequential assembly pathway, with a progressive increase in the stability of the complex as more subunits are incorporated.

\section{Complexes and sub-complexes: hints to the assembly pathway}

In this section, we will summarize our current understanding of the mechanisms of assembly of the other complexes. As very few real kinetic data are available, we will rely mostly on in vitro studies of the biochemical stability of the interactions between subunits and on mutant studies suggesting the occurrence of intermediate stages of assembly.

\subsection{Photosystem II}

PSII is by far the photosynthetic complex for which biochemical and genetic dissection has been analyzed in greatest detail. The smallest preparation able to perform the basic reaction of photosystem II contains six polypeptides: D1 and D2 subunits (homologous to the L and M subunits of the bacterial reaction center), the $\alpha$ and $\beta$ subunits of cytochrome $b_{559}$, and two polypeptides with a single membrane-spanning helix, PsbI and PsbW. Larger complexes have been isolated which contain in addition the CP47 chlorophyll $a$-binding protein and PsbT, plus PsbL and PsbK [39]. The latter preparation is a dimer, as is probably the case for PSII in situ. The classical PSII core preparations contain additional integral subunits, among which the CP43 antenna protein. The nuclearencoded extrinsic polypeptides (OEE1, OEE2 and OEE3) bind to the lumenal surface where they concur to the stabilization of the oxygen-evolution site. Higher order structures have been isolated from higher plants, where PSII arranged as a dimer is surrounded by the nucleusencoded chlorophyll $a / b$-binding proteins, forming various types of functional units $[40,41]$.

The picture emerging from developmental, genetic and time-resolved biochemical studies of PSII assembly appears somewhat more complex: clearly, biological assembly is not the exact reverse of biochemical disassembly. Two types of processes must be considered, although they may overlap at times: the mechanisms through which a PSII unit is built up in a developing chloroplast and those that insure its maintenance in the mature organelle.

PSII activity is absent in etioplasts and appears during greening, a process that has been extensively studied in plants $[42,43]$ and in the $y 1$ mutant of Chlamydomonas that does not synthesize chlorophyll in the dark [44]. The mRNAs for D1, D2, CP47 and CP43 (i.e., the chlorophyll- binding polypeptides) are present in etioplasts, but their translation products are not detected. Light triggers accumulation of these polypeptides, maybe by a direct effect on translation [45], or most probably by allowing chlorophyll synthesis required for stabilization of the apoproteins [46, 47]. But many PSII proteins do not share this strict requirement for light. Cytochrome $b_{559}$, PsbW, PsbH and PsbS are present in etioplasts, as are the extrinsic OEE1 and OEE2 polypeptides [42]. Their relative amounts increase during greening, significantly faster than that of the chlorophyll $a$-binding proteins [42], so that the latter will meet a large pool of their assembly partners as they enter the membrane. This raises the question whether these components are assembled in etioplasts and whether they can serve as a nucleus for the assembly of the chlorophyll $a$-binding proteins. Recently, cytochrome $b_{559}$ has been detected in 90-200 kDa complexes in barley etioplast membrane [48].

Genetic studies may indirectly reveal intermediate steps in the assembly of PSII. As a rule, mutations in genes coding for the chlorophyll-binding subunits affect the stability or synthesis of most of their assembly partners. Mutants devoid of D1 are severely depleted in D2 and CP47, and vice versa [49]. CP43 seems to be somewhat more independent, since CP43-less mutants still can accumulate sizeable amounts of D1, D2 and $\mathrm{CP} 47$, assembled in a detergent-stable complex, and conversely $\mathrm{CP} 43$ can accumulate to some extent in mutants lacking D1, D2 or CP47 [50]. But by and large, the four chlorophyll $a$-binding subunits seem to depend on each other for their accumulation in the membrane.

In contrast, cytochrome $b_{559}$, although it is part of the reaction center complex, accumulates to normal levels in the absence of the chlorophyll-binding subunits. This has been observed in D1-less mutants of Chlamydomonas [51], barley [52, 53] and Synechocystis [54]. The converse is not true, since both the $\alpha$ and $\beta$ subunits of cytochrome $b_{559}$ are necessary for PSII biogenesis [51, 55]. Similarly, the nuclear-encoded OEE1, OEE2 and OEE3 polypeptides accumulate to normal levels in mutants lacking polypeptides D1, D2, CP47 or CP43 [50], consistent with their presence in etioplasts and in dark-grown $y 1$ cells, while mutants lacking the OEE proteins still stably accumulate the rest of the PSII in the membrane. Interestingly, OEE1 appears to depend on cytochrome $b_{559}$ for its stability, as the cytochrome $b_{559}$ mutant of Chlamydomonas completely lacks OEE1 [51]. This places cytochrome $b_{559}$ at a cross-road of PSII assembly. In vir ${ }^{115}$, cytochrome $b_{559}$ and OEE1 segregate to the appressed regions of the thylakoid membrane, in contrast to the traces of CP47 and CP43 which are randomly distributed in the two domains [52]. Preferential localization of OEE1 to the appressed regions has also been reported for Chlamydomonas mutants lacking proteins D1, D2 or CP47 [50]. Since the lumenal OEE1 cannot by itself sense the appression state on the stromal surface, it has been proposed that cyto- 
chrome $b_{559}$ (possibly associated with other PSII polypeptides) serves to anchor it to the membrane [52]. However, chemical cross-linking studies argue against strong binding of OEE1 to the etioplast membrane [56]. CP47 and D1 subunits have also been implicated in binding OEE1 [57, 58].

In Chlamydomonas PSII mutants [50] and in darkgrown $y l$ [44], OEE2 and OEE3 also accumulate normally, although their association with the membrane is weaker than in WT. OEE2 is randomly distributed between appressed and non-appressed regions in the absence of CP43, but its distribution seems to follow that of CP43 in D1 or D2 mutants, consistent with a preferential binding to CP43. In vitro, rebinding of OEE2 and OEE3 to PSII-membranes requires OEE1 [57], but mutant data argue for OEE1-independent binding in vivo [50]. It should also be noted that a substantial fraction of the OEEs can be easily released from thylakoids, upon sonication, Triton X-100 treatment [59] or freeze-thawing [11]. Free OEEs (either newly imported or released during photoinhibition) are rather stable in the lumen, but OEE3 can be cleaved by a prolyl endopeptidase [60].

Many small subunits of PSII appear to be dispensable for assembly or even for function, although their stabilization may require assembly of PSII. Such is the case for PsbT [61], PsbU [62] and even for PsbI, a component of the reaction center itself $[63,64]$. Those mutants only displayed various level of reduction in PSII accumulation or light sensitivity. Deletion of psbL in Synechocystis allows partial assembly of a non-functional complex, and readdition of PsbL restores $\mathrm{Q}_{\mathrm{A}}$ reduction $[65,66]$. While $p s b H$ and $p s b K$ mutants of Chlamydomonas were not photosynthetic and failed to assemble PSII [67, 68], the corresponding mutants of Synechocystis only displayed light-sensitivity [69, 70]. In general, mutations in structural genes are better tolerated in the cyanobacterium [71], perhaps revealing a less efficient degradation system or a more active biogenesis.

Light is a major developmental factor of PSII biogenesis, as a trigger of the greening process. But it also plays an important role in mature chloroplasts, when biosynthetic process are harnessed to the maintenance of the photosynthetic apparatus. Charge separation in PSII may lead to the generation of highly reactive chemical species that can damage the center. At high fluence rates, the cell's ability to repair PSII centers may be overwhelmed, which results in a decline in PSII activity described as photoinhibition [72, 73]. Two types of mechanism have been observed depending on experimental conditions. Acceptor side photoinhibition involves double reduction of $\mathrm{Q}_{\mathrm{A}}$, leading to increased $\mathrm{P} 680^{+}-\mathrm{Pheo}^{-}$charge recombination, production of ${ }^{3} \mathrm{P} 680$ and generation of singlet oxygen. In donor side models, inactivation of oxygen evolution results in generation of the highly oxidizing $\mathrm{Tyr}_{\mathrm{Z}}{ }^{+}$and $\mathrm{P} 680^{+}$cations.
In the initial phase of photoinhibition, conformational changes occur in PSII that together with unidentified modifications of the D1 polypeptide commit the latter to degradation. These include monomerization, conversion of cytochrome $b_{559}$ from the high potential to the low potential form [74] and possibly separation of CP43 from the PSII unit [75]. Monomeric PSII migrates to the stroma lamellae, where damaged D1 is degraded and replaced by a newly-synthesized polypeptide [76] concomitantly with degradation of PsbW [77]. Monomerization appears to require dephosphorylation of the inactivated D1 protein $[78,79]$, and may in turn be necessary for migration to stroma lamellae. D1 is not phosphorylated in cyanobacteria, Chlamydomonas, ferns and mosses [80, 81], which suggests that the protective role of phosphorylation has been acquired recently in evolution. After replacement of D1, new structural changes including dimerization, migration to grana stacks and interaction with LHCII complete the cycle of PSII repair.

D1 degradation appears to be a two-step process, as judged from the transient appearance of intermediate degradation products both in vivo and in vitro. Their size differs in donor side versus acceptor side photoinhibition, and both types of cleavage may occur in vivo $[82,83]$. The initial D1 cleavage can be obtained in purified reaction centers, which has led to the suggestion that it is autocatalytic [84]. This endoproteolytic step appears to be stimulated by GTP, while further degradation involves an ATP-dependant metalloprotease [85, 205]. In PSII core particles or trypsin-treated membranes, the latter reaction can be restored by the membrane-bound FtsH protease, albeit with low efficiency [205]. The stromal Clp protease may also be involved, at least in some forms of photoinhibition. In Synechococcus, one of the clpP genes is up-regulated during light stress, but its inactivation does not reduce the rate of D1 degradation [86]. However, the deleted strain was unable to adapt to UV-B irradiation [87] which is known to induce a specific form of photoinhibition involving D1 degradation [88]. Other evidence for a role of Clp proteases in photoinhibition has come from studies of Chlamydomonas ATP synthase mutants. In these strains, PSII is highly sensitive to light and the degradation of PSII subunits is slowed down in a mutant with reduced $c l p P$ expression (Majeran et al., submitted).

The first cleavage event, at least in donor side photoinhibition, does not seem to require disassembly of PSII since D1 degradation products appear in gradient fractions containing assembled PSII during photoinhibition [75, 83]. OEEs and Mn atoms are released into the lumen [58, 89], probably as a consequence of D1 degradation, but the D1-less PSII unit appears to be maintained, as a substrate for D1 re-assembly (see below). However, such a D1-less core is not expected to remain indefinitely stable in the membrane, so that the fate of the other PSII subunits is expected to depend on the rate of D1 synthesis. Indeed, degradation of other PSII subunits has been reported, 
mostly in in vivo studies involving strong or prolonged illumination. After D1 and PsbW, D2 appear as the most sensitive [90], but CP47 and CP43 and even cytochrome $b_{559}$ can be degraded as well [91-93]. Clearly, the ability to restore a functional PSII unit after photoinhibition will depend partly on the ability to keep PSII in a reactivable form, either through reversal of the inactivation process or through de novo D1 synthesis. Interaction with molecular chaperones may participate in the photoprotection of PSII. Aggregates have been observed between D1 and other PSII subunits and they can be resolved by addition of stromal fractions which may include proteases and chaperones [94]. In Chlamydomonas, overexpression of the chloroplastic Hsp70 has been shown to protect from photoinhibition and to enhance recovery, while anti-sense constructs that prevented the light-induced increase in Hsp70 had the opposite effect [92].

During photoinhibition, synthesis of D1 is enhanced, resulting from an increase in $p s b A$ transcripts and in translation initiation [95]. Increased D1 synthesis seems to be a consequence of $\mathrm{D} 1$ degradation, rather than of the light treatment itself. In cytochrome $b_{6} f$ mutants, PSII inactivation is retarded and D1 is not degraded as long as the plastoquinone pool is maintained reduced [96]. In those conditions, no increase of D1 synthesis is observed. Apparently, a D1-less complex is a required partner for productive D1 translation.

Even at light intensities below saturation for photosynthesis, D1 turns over substantially faster than the other PSII subunits [97], so that studies of the biogenesis of D1 in low light are also relevant to PSII repair during photoinhibition (see section 6). The preferential labeling of D1 has been exploited to study the time course of its membrane integration and association with its assembly partners. D1 is synthesized on membrane-bound ribosomes [98] and inserted cotranslationally in the membrane. $\mathrm{D} 1$ elongation is stimulated by a light-driven $\Delta \mathrm{H}^{+}$ [99]. Newly synthesized D1 appears initially in stroma lamellae [97], where its proteolytic processing occurs (i.e., removal of its $\mathrm{C}$-terminal tail by the lumenal CtpA protease, allowing liganding of the manganese cluster and oxygen evolution [100]). During the elongation of D1, ribosomes pause at specific sites, leading to the formation of well-defined translation intermediates. The most prominent ones (17 and $24 \mathrm{kDa}$ ) correspond to the exit from the ribosome of the second and fourth transmembrane helices, respectively [101, 102]. Ribosome pausing has been suggested to be required either for the binding of pigments to apo-D1 or for the proper insertion of the nascent chain in the thylakoid membrane. Indeed, D1 has to bind chlorophyll $a$ and $\beta$ carotene to become fully functional and failure to bind these pigments leads to an early degradation of the protein. In pulse experiments performed on etioplasts, no full length translation product can be detected, but rather degradation products of $23 \mathrm{kDa}$, suggesting a competition between assembly and degrada- tion processes during D1 synthesis [103]. Supplementation of etioplasts with in vitro synthesized chlorophyll $a$ or Zn-Pheophytin restores the stable accumulation of D1 [46, 104], but presence or absence of chlorophyll has no consequences on the pattern of ribosome pausing [47]. Thus, ribosome pausing is more likely required to facilitate the folding of the nascent polypeptide, its insertion in the membrane and the various interactions that would lead to its assembly into a PSII complex. Ribosome pausing is developmentally regulated, increasing in intensity as the leaf ages, which may indicate a specific link to PSIIrepair, as opposed to de novo synthesis of PSII units.

Early biochemical studies $[105,106]$ suggested that D1 can associate directly with a pre-formed PSII core complex. Recently, by refining their solubilization conditions, van Wijk and collaborators have demonstrated cotranslational assembly of D1 within the PSII unit [107]. After a 2.5 min labeling pulse, D1 appears into fractions corresponding to the reaction center complex and to larger monomeric complexes with CP47 and CP43 attached. Even the precursor form is never found free in the membrane, confirming that assembly precedes C-terminal processing [108]. Perhaps the most spectacular finding of van Wijk and collaborators is that D2 and CP47 interact with D1 nascent chains, i.e., during translation elongation [107]. In ribosome nascent chain complexes, anti-D2 and anti-CP47 antibodies can immunoprecipitate D1 and its $17 \mathrm{kDa}$ and $25 \mathrm{kDa}$ translation intermediates. The reason for the slow rate of translation elongation and for ribosome pausing may be to allow escape of pairs of transmembrane helices from the putative translocon channel and their interaction with D2. Hence, the picture that emerges is that of a tight coordination of D1 translation with its integration into the preexisting core complex. This complex would contain at least D2 and CP47, probably associated with PsbI and cytochrome $b_{559}$ which had been shown earlier to interact rapidly with D1 [108]. The vir ${ }^{115}$ gene product may be necessary for this interaction to occur in mature chloroplasts, while a different pathway would prevail during greening, when pauses are less abundant [101] and the vir ${ }^{115}$ gene product is dispensable for productive D1 translation [109]. Recently, trace amounts of D2 have been found in etioplast membranes, migrating as a high $M_{\mathrm{r}}$ complex [48]. In that study, newly synthesized D1 appeared in 45-90 kDa fractions, suggesting that D1 incorporates directly into some kind of complex. D1 assembly in etioplasts may be cotranslational as well, but the recipient complex clearly differs from that in mature chloroplasts.

\subsection{Photosystem I}

The structure of PSI, as described by biochemical [110] and X-ray crystallographic studies [111] resembles somewhat that of PSII, probably indicative of a common origin [112]. The core of PSI is composed of chloroplast- 
encoded subunits, the large intrinsic homologous PsaA and B subunits that bind chlorophyll $a$ and most of the cofactors of electron transport, plus $\mathrm{PsaC}$ which carries two Fe-S clusters. The isolated center contains also several small intrinsic chloroplast- or nucleus-encoded subunits (PsaI, J, M and PsaF, G, H, K, L, respectively). In addition, three nucleus-encoded extrinsic polypeptides are found, either on the stromal surface (PsaD and E, serving in binding ferredoxin and ferredoxin-NADP-reductase) or on the lumenal surface (PsaN, absent in cyanobacteria). In the crystal structure at $4 \AA$ resolution, 34 transmembrane and nine surface helices can be identified, some of which ascribable to a particular subunit. The cofactors of electron transfer are gathered around a central symmetry axis relating PsaA and $\mathrm{B}$ and $\mathrm{PsaD}$ and $\mathrm{E}$. The PsaC polypeptide sits in the middle, on the stromal surface. In the membrane intrinsic part, antenna chlorophylls are separated form the central domain by the N-terminal helices of PsaA and $\mathrm{B}$, while the smaller intrinsic subunits constitute an outer shell, with some contribution to chlorophyll binding $[111,113]$.

This concentric organization is reflected in biochemical and genetic studies of the assembly of the complex. The large PSI unit isolated from plants [114] can be separated into a peripheral chlorophyll $a / b$ antenna and a core complex carrying out the photochemical reactions. The latter can be progressively trimmed by further detergent treatment down to a CPI preparation capable of P700 photooxydation, containing only PsaA and PsaB. In particular, PsaF could be removed by Triton X-100 concomitantly with loss of plastocyanin photooxidation, while SDS caused loss of PsaE together with $\mathrm{NADP}^{+}$photoreduction [115]. The extrinsic PsaC, D and E subunits can be reassembled onto salt-washed reaction centers or membranes from deletion mutants. This has allowed detailed studies on their requirements for binding [116-119], showing that binding is sequential but cooperative in most cases. PsaC is required for the binding of PsaD and $\mathrm{E}$ [120], but the presence of PsaD stabilizes PsaC [121] and PsaE binds better in the presence of PsaD [122]. Developmental studies in greening plastids confirm the central role of PsaA/B as a nucleus around which other subunits assemble: the $p s a D$ and $E$ genes are expressed only after the onset of accumulation of $\mathrm{PsaA} / \mathrm{B}$, consistent with a sequential assembly process [110].

From the study of deletion mutants in Synechocystis, it appears that in vivo assembly of the PSI center is a robust process, even more so than that of PSII. Synechocystis mutants in psaE, $F, L, I$ and $J$ are still capable of photoautotrophic growth, even though specific defects have been described, respectively in linear and cyclic electron transport [123, 124], $\mathrm{Mg}^{2+}$ requirement [125], trimerization and PsaD binding [126, 127], stability of PsaL [128] and of PsaF [129]. However, photosynthesis was severely reduced in mutants of psaD [130], and completely impaired in the psaA, $B$ and $C$ mutants [120,
131, 132]. The psaC mutant can still assemble a PsaA/B heterodimer and PsaF, but both PsaA and PsaB are required for the stable membrane association of any PSI polypeptide. Little information is available for the role of PsaG, $\mathrm{H}$ and $\mathrm{K}$ which are nucleus-encoded in plants, but they may be expected to be largely dispensable for PSI assembly since they are absent in cyanobacteria. In Chlamydomonas, deletion and site-directed mutants are available for PsaA, B, C, F and J [133-138], and their phenotypes are largely congruent with those of the cyanobacterial mutants. As already noted for PSII, these mutations prove generally more destabilizing to the whole complex than in Synechocystis, for example the psaC mutant completely lacks PsaA/B [136].

\subsection{ATP synthase}

$\mathrm{H}^{+}$-driven ATP synthases utilize the $\mathrm{H}^{+}$gradient generated by an electron transfer chain to synthesize ATP at the expense of ADP and Pi [139]. The enzyme is composed of two sub-complexes, called $F_{1}$ and $F_{0}$ in bacteria and mitochondria, $\mathrm{CF}_{1}$ and $\mathrm{CF}_{0}$ in chloroplasts. The intrinsic $\mathrm{CF}_{0}$ and extrinsic $\mathrm{CF}_{1}$ can be extracted and purified either together or separately and reconstituted in vitro [140, 141]. The 3-D structure of the mitochondrial $F_{1}$, alone or complexed with part of $\mathrm{F}_{0}$, has been elucidated at atomic resolution $[142,143]$, shedding light on the mechanism of the enzyme. It also allows a better understanding of how it is assembled in vivo or reconstituted in vitro.

The $\mathrm{CF}_{0}$ moiety can be described as combining a stator (subunit IV and the two homologous subunits I and II) and a rotor composed of a ring of the highly hydrophobic subunit III, the 'proteolipid'. The stoichiometry has been described as 1:1:1:12, but the recent crystal structure of the mitochondrial enzyme contains only 10 proteolipid subunits [143]. The proteolipid oligomer is held by strong interactions: it can be preserved through gel electrophoresis even after boiling in SDS (Vallon, unpublished). Purified CF1 is composed of five subunits, $\alpha, \beta, \gamma, \delta$ and $\varepsilon$, in the stoichiometry $3: 3: 1: 1: 1$. In vitro, the $\alpha$ and $\beta$ subunits can be reconstituted together as $(\alpha \beta)$ dimers or $(\alpha \beta)_{3}$ hexamers with the help of chloroplast chaperones. This core is further stabilized when the $\gamma$ subunit binds, which also allows interaction with the inhibitory $\varepsilon$ subunit $[144,145]$. In $\mathrm{CF}_{1}$-stripped thylakoids, the $\gamma, \delta$ and $\varepsilon$ subunits together can 'plug' the $\mathrm{H}^{+}$leak in open $\mathrm{CF}_{0}$ complexes [146]. During catalysis, protons from the lumenal side are thought to reach a critical Asp residue in subunit III, then be expelled to the stromal side via a proton channel in subunit IV. This would cause rotation of the ring of subunits III and of the associated $\gamma / \varepsilon$ stalk. Rotation of the $\gamma$ subunit would trigger conformational changes in the $(\alpha \beta)_{3}$ core permitting ATP synthesis.

In vivo assembly studies of chloroplast ATP synthase have been led mostly in Chlamydomonas. In all the mutants available, lack of one subunit results in complete 
impairment of function [147-149]. However, the exact effect on the accumulation of the other subunits varies with the mutation, reflecting differences in the stability of the assembly intermediates.

In general, mutants defective in $\mathrm{CF}_{0}$ subunits allow some accumulation of relatively large amounts of at least some $\mathrm{CF}_{1}$ subunits. For example, strain ac46 is devoid of $\mathrm{CF}_{0}$ subunit III because it lacks the atpH transcript (Drapier, personal communication). It is also unable to synthesize subunit IV, whereas subunit I is integrated into the membrane at a normal rate [147]. In this strain, the $\mathrm{CF}_{1}$ subunits are synthesized normally but they do not bind to the membrane. A large part is rapidly degraded, but the rest appears to assemble into a partial $\mathrm{CF}_{1}$ complex: the cell accumulates 35-40\% of the normal content of $\alpha$, $\beta$ and $\gamma$ in the stroma, while $\delta$ is almost undetectable. These levels do not decrease when the cell enters stationary phase, suggesting a stable assembly of $(\alpha \beta)_{3} \gamma$ (unpublished results). In FUD18 which lacks subunit I of $\mathrm{CF}_{0}$, $\mathrm{CF}_{1}$ also does not bind to the membrane. But FUD23, a strain lacking synthesis of subunit IV, binds sizeable amounts of $\alpha, \beta, \gamma$ and $\varepsilon$ of $\mathrm{CF}_{1}$ on its membrane [147] and one may wonder whether subunit III whose synthesis is normal in this mutant may by itself serve as a $\mathrm{CF}_{1}$ binding site.

In contrast, the stability of $\mathrm{CF}_{0}$ appears to depend heavily on the presence of $\mathrm{CF}_{1}$. All the ATP synthase mutants lacking a $\mathrm{CF}_{1}$ subunit appear to lack all $\mathrm{CF}_{0}$ subunits and have a low $\mathrm{H}^{+}$conductance $[147,150] . \mathrm{CF}_{0}$ subunits are synthesized normally in a 5' pulse, but they fail to accumulate, indicative of rapid degradation. This is true also for some mutants that are still able to assemble a partial $\mathrm{CF}_{1}$ in the stroma. A mutant lacking $\gamma$ [151] accumulates $15-25 \% \alpha$ and $\beta$ (Drapier, personal communication), probably in an assembled form. The FUD17 mutant, with a frameshift in the atpE gene encoding the $\varepsilon$ subunit [152], also accumulates high levels of $\alpha$ and $\beta$ ( $\gamma$ was not investigated) [147]. In this case, a small fraction appears to associate with the membrane. In contrast, mutants lacking $\beta$ fail to accumulate any of the other $\mathrm{CF}_{1}$ polypeptides [147-150], while a mutant that does not translate $\alpha$ can accumulate $\beta$ (but no other $\mathrm{CF}_{1}$ subunit) in a soluble form [153]. An early interaction between $\alpha$ and $\beta$ is demonstrated by the study of the FUD16 mutant [147, 154]. This mutant carries two point mutations in the atpA gene for $\alpha$, causing its over-accumulation in an aggregated state. These chloroplast inclusion bodies contain also large amounts of $\beta$, but no subunit $\gamma$. A low level of ATPase activity can be detected on the membrane, probably as a result of escape from the aggregation pathway. Interestingly, accumulation of $\alpha$ and $\beta$ was totally prevented when an additional mutation was introduced reducing the rate of translation of $\alpha$. Clearly, aggregation of the mutated form of $\alpha$ requires a high rate of translation. When overexpressed in E. coli, $\mathrm{CF}_{1}-\alpha$ generally aggregates, while $\beta$ remains in a soluble form $[155,156]$. Since refolding of $\alpha$ after urea denaturation can be promoted by Mg-ATP binding [156], it can be speculated that the FUD16 mutation causes aggregation by impairing the ATP binding site nearby.

In summary, assembly of the ATP synthase appears to involve a variety of inter-subunit interactions within $\mathrm{CF}_{0}$ or $\mathrm{CF}_{1}$ and between these sub-complexes. The partial complexes that can be accumulated in ATP synthase mutants include isolated $\beta$ (but none of the other subunits), $\alpha \beta$ complexes with or without $\gamma$ and possibly a membrane-bound $\mathrm{CF}_{1}$-subunit III complex. In addition, $\alpha$ and $\beta$ can aggregate when folding of $\alpha$ is perturbed. All these objects are subject to proteolysis, sometimes in kinetic competition with assembly. The proteases involved are not identified, but the ClpP protease appears to control the level of accumulation of $\beta$ in the $\alpha$-less mutant (Vallon, unpublished). As is true for the other complexes, all these sub-complexes do not necessarily represent true intermediate stages of assembly. More work is needed to characterize precisely the sub-complexes formed in WT and mutant chloroplasts, and to identify those involved in regulating translation of atp genes (see section 4).

\section{Regulation of translation by assembly: control by epistasy of synthesis}

As outlined in the previous sections, assembly controls not only the stability of newly synthesized polypeptides, but also for some of them their translation rate, a phenomenon described as control by epistasy of synthesis (CES) $[32,33]$. Thus, there is a hierarchical organization in the expression of the subunits of a complex. The CES subunits are those whose rate of synthesis is dependent upon the presence of some assembly partners, called dominant proteins.

Mutant studies in Chlamydomonas show that in each complex of the thylakoid membrane, at least one subunit is under epistatic control. As detailed above, mutants lacking cytochrome $b_{6}$ or subunit IV exhibit a reduced rate of synthesis of cytochrome $f[24,33]$. Similarly, the PsaA protein is not synthesized in mutants lacking PsaB or expressing an unstable mutated version of it, whereas mutants lacking PsaA in contrast show normal translation of PsaB, followed by rapid degradation [133, 157]. The core subunits of PSII are also under translational control, since D1 mutants show a reduced synthesis of CP47 [50, $158,159]$, and D2 mutants of D1 and CP47 [50, 160]. This can be described as an epistatic cascade, where D2 appears necessary for D1 synthesis, which in turn is required for that of CP47. In the ATP synthase, the synthesis rate of the $\alpha$ subunit is considerably decreased in mutants lacking the $\beta$ subunit, while mutants with reduced or abolished translation of subunit $\alpha$ present a stimulation of $\beta$ synthesis [147, 153, 154]. The FUD16 mutant producing an aggregation-prone $\mathrm{CF}_{1}-\alpha$ presents oversyn- 
thesis of both $\alpha$ and $\beta$ [154]. Rubisco also is under epistatic control, since a mutant lacking the small subunit shows a reduction in translation of the chloroplastencoded large subunit [161].

Evidence for such a control of translation by assembly is not limited to Chlamydomonas. In the vir ${ }^{115}$ mutant of barley, primarily impaired in the expression of D1, synthesis of CP47 is also reduced [53, 109]. Although one cannot exclude a dual effect of the mutation on the expression of both polypeptides, this observation is easily understood if CP47 is a CES protein in barley as it is in Chlamydomonas. In tobacco, antisense plants with reduced expression of the small subunit of Rubisco also show a decreased synthesis of the large subunit [162]. Epistatic mechanisms may even contribute to the biogenesis of mitochondrial complexes: in the yeast Saccharomyces cerevisiae, the rate of synthesis of the mitochondrion-encoded COXI, but not its half-life, is reduced when the cytochrome oxidase complex does not assemble due to the absence of other COX subunits [163, 164]. Mutants deficient for the synthesis of subunit 9 of the mitochondrial ATP synthase show reduced synthesis of Atp6 and Atp8 [165, 166].

In all cases, the dominant/CES couples are pairs of polypeptides that are in close contact in the final complex. So it is tempting to propose that the control is mediated by a protein motif carried by the CES subunit, as has been demonstrated for cytochrome $f$. This motif, shielded upon assembly, would exert a negative feed-back on the synthesis of the CES protein. Since it should interact with the translation machinery, the motif is rather to be found on the stromal face of the membrane. A prerequisite for autoregulation is that the CES protein be at least marginally stable in the non-assembled state. Indeed, the low amounts of the CES proteins translated in situations of regulation (cytochrome $f, \mathrm{D} 1, \mathrm{CP} 47, \mathrm{CF}_{1}-\alpha$ ) have been found fairly stable in pulse chase experiments $[24,50$, 153]. Other types of mechanisms, e.g., a positive feedback exerted by a motif present on the dominant subunit, can also be envisioned. The exact mechanisms by which PsaB, $C_{1}-\beta, \mathrm{D} 2$ or $\mathrm{D} 1$ control $p s a A, a t p A, p s b A$ and $p s b B$ translation, respectively, remain to be elucidated. Clearly, only site-directed mutagenesis can unambiguously identify the regulatory motifs in epistatic processes and test the generality of the model. This was conveniently achieved for cytochrome $f$ by deleting the C-terminal stromaexposed domain, the most likely candidate [33, 34].

In the case of the ATP synthase $\mathrm{CF}_{1}$, the situation is rather complex: not only is $\alpha$ under epistatic control of $\beta$, but synthesis of $\beta$ is stimulated in the absence of $\alpha$. The latter observation is unique in the biogenesis of the thylakoid membrane and suggests that $\alpha$ negatively controls atpB translation [153]. Although epistasy in $\mathrm{CF}_{1}$ can be modeled with free unassembled subunits, a role can also be envisioned for the $\alpha \beta$ dimers. They could for example be responsible for the negative control of atp $B$ : in this way, the downstream steps of assembly could control production of the building blocks (Rimbault et al., personal communication).

In the case of petA, the CES process is exerted at the level of translation initiation: the 5'UTR of the mRNA is able to confer epistatic control to a reporter gene. Although other mechanisms can be envisioned, this seems to be the general strategy of epistatic systems. In the ATP synthase of Chlamydomonas, epistatic control of $\alpha$ by $\beta$ and overexpression of $\beta$ in the absence of $\alpha$ are mediated at the level of translation initiation: cytochrome $f$ synthesis driven by atpA or atpB 5'UTRs is respectively repressed in the absence of $\beta$ or stimulated in the absence of $\alpha$ (Rimbault et al., personal communication). The same seems true for Rubisco: in tobacco antisens plants with a reduced expression of the small subunit, the amount of $r b c L$ mRNA, encoding the large subunit is unaffected but its binding to polysomes is reduced suggesting a specific decrease in translation initiation [162]. It has been recently reported that translation initiation of D1 is decreased in a Chlamydomonas mutant lacking D2 [167]. The situation with PsaA is less clear: expression of a reporter gene translated under control of the psaA 5'UTR was found dependent upon the presence of PsaB in one case, but not in an other, depending on the reporter gene used [157] (Wostrikoff et al., unpublished results). It seems unlikely that all those CES proteins that are regulated at the level of translation initiation have evolved a specific RNAbinding motif able to bind their own messenger 5'UTR. The interaction is more likely indirect and will rely on ternary effectors able to modulate translation efficiency, depending on their fixation to the regulatory motif. The various nuclear-encoded translation factors, whose regulatory function is still pending, could turn out to play an important role in the assembly of complexes through translational autoregulation of CES polypeptides.

It should be stressed that the CES process, best characterized in mutants deficient in the assembly of a complex, also operates in the wild type. It participates in the fine tuning of subunit production, as shown by the three-fold overexpression of cytochrome $f$ in mutants lacking the regulatory motif. Since it concerns a limited subset of chloroplast encoded proteins, its energy-saving role in preventing excess production of useless subunits is only limited. Rather, the unique properties of the CES proteins offers a mean to facilitate sequential multistep assembly. Dominant proteins are in general quite unstable. To be efficient, assembly must be kinetically favored over the competing degradation process. The dominant polypeptides will meet as they enter the membrane low but stable amounts of unassembled CES subunits, available for a rapid interaction that will protect them from degradation. Conversely, the stability of the CES proteins makes it almost mandatory to control their synthesis, otherwise they may accumulate in excess. A particularly interesting case is that of the epistatic cascade of PSII 
which parallels the structural organization of the PSII unit. Epistasy would ensure that D1 is only synthesized when D2, with which it interacts cotranslationally, is present. Then, the D1-D2 reaction center will allow the synthesis of CP47, the next subunit in the hypothetical assembly pathway. Note that partial assembly does not always stabilize a protein: D1, being a CES protein, is poorly translated in the absence of D2, but is stable in the membrane. In contrast, it is synthesized at wild type rate and rapidly degraded in mutants deficient for the synthesis of CP43. Ironically, while unassembled D1 is not a target for proteases, it becomes one upon partial assembly with D2 and CP47 [50].

\section{Catalysts of membrane integration and assembly}

As may appear from the above description of assembly, many of the important decisions in the life of a polypeptide are taken at the time of its integration into the membrane. All the chloroplast-encoded thylakoid membrane proteins (and many soluble proteins as well) are translated on membrane-bound ribosomes [168, 169]. Those that are imported from the cytoplasm are targeted to the membrane by signals found in the mature protein or in an N-terminal signal peptide that is cleaved after translocation to the lumenal space. Understanding how translational regulation is achieved, how a polypeptide enters the assembly or the degradation pathway, how cofactors find their way to their site in the protein etc, requires a better knowledge of the state of the polypeptide as it enters or crosses the membrane and of the proteins with which it may interact at this stage. In vitro, some integral proteins can insert into the thylakoid membrane spontaneously, i.e., with no apparent requirement for a proteinaceous insertion apparatus or energy source [43, 170-172]. In most cases, however, integration or translocation of the protein is mediated by one of three specific pathways that the chloroplast has inherited form its eubacterial ancestor [173].

The Tat pathway is involved in the translocation of OEE2, OEE3, PsbT, PsaN and the Rieske protein. As a result, the maize hcflo6 and that mutants which lack the homologues of the bacterial TatA and TatB proteins, respectively $[174,175]$, have pleiotropic deficiencies in most of the complexes of the membrane. The name Tat stands for twin arginine translocation, because its substrates generally have two arginines at the N-terminal boundary of the hydrophobic part of their signal peptide $[176,177]$. Like its bacterial homologue, it is strictly dependent on the presence of a transmembrane $\Delta \mu \mathrm{H}^{+}$. The Tat system appears devoted to the translocation of tightly folded proteins, presumably after their cofactors have been attached in the cytoplasmic/stromal compartment. It has even been suggested that folding is a prerequisite for translocation and that the system has a proofreading function, avoiding export of cofactor-less or misfolded proteins. Most of the Rieske protein imported in organello associates with the stromal surface of the membrane in a protease-sensitive form [31], which may be due to inefficient association of the iron-sulfur cluster. However, mutations in the Rieske protein impairing binding of the Fe-S cluster do not prevent its translocation and assembly with the complex [178], so that this may not be true in all cases. The Sec-dependent pathway also directs translocation of lumenal (plastocyanin, OEE1) and membrane anchored (cytochrome $f$, PsaF) polypeptides [179]. Translocation requires ATP, is blocked by azide and facilitated by a transmembrane $\Delta \mu \mathrm{H}^{+}$. SecA interacts with the substrate on the stromal surface, while translocation is operated through a transmembrane complex (translocon) involving at least the SecY and SecE homologues [180].

In contrast, the signal recognition particle (SRP) pathway appears specialized in the insertion of polytopic integral proteins. Chloroplastic SRP is composed of two polypeptides of $54 \mathrm{kDa}$ and $43 \mathrm{kDa}$, but differs from its eubacterial homologue in lacking an RNA component [181]. One role of SRP in vivo seems to be the maintenance of newly imported light harvesting chlorophyll $a / b$ proteins (LHCPs) in a soluble form, and together with the chloroplast equivalent of FtsY, to promote their integration into the membrane in a GTP-dependent reaction [182-185]. LHCPs can associate spontaneously to the thylakoid, due to their hydrophobic characteristics. However, this associated form is not protected against protease digestion, in contrast to the form produced by SRPdependent translocation $[172,186]$. Integration is thought to occur on stroma lamellae. The following events of chlorophyll binding, trimerization, association with the reaction centers and migration to grana stacks probably are spontaneous events that can be observed in vitro [187, 188]. Although the severity of thylakoid biogenesis defects in secY mutants [189] had led to the hypothesis that the SRP pathway also uses SecY in the translocation step, in vitro studies rather indicate that SecY functions only in the SecA-dependent pathway $[180,190]$. The recently identified Oxa1p translocase appears instead as responsible for integration of LHCP [191].

In addition to LHCPs, SRP54 may also be implicated in the biogenesis of chloroplast-encoded polytopic membrane proteins. In vitro, an interaction has been observed between cpSRP54 and a specific subset of thylakoid protein precursors, those with particularly hydrophobic signal sequence, including the chloroplast encoded cytochrome $f$ [192]. Furthermore, cross-linking studies have shown a close association of SRP54 (but not SRP43) with D1 during the early stage of its translation [193]. Mutants lacking cpSRP43 show reduced LHCP content but normal accumulation of reaction center polypeptides [194, 195], while mutants of SRP54 have yellow first true leaves, show delayed chloroplast differentiation and present a reduction in the accumulation of seven (out of 11) LHCP 
proteins and of the reaction center proteins D1, D2 and PsaA/B [194, 196]. A reduction in LHCP and D1 content has also been observed in a cytochrome $f$ signal sequence mutant [206], suggesting that the translocation machineries for these proteins partly overlap.

The main function of the systems described above is in translocation, rather than in assembly per se. Whether specific assembly catalysts operate in the thylakoid membrane is still a matter of debate. An assembly catalyst would allow specific steps of the sequential assembly of a complex, without being itself part of the final protein. Such could be the case for the Ycf3 and Ycf4 proteins which are required for PSI accumulation (whereas many PSI subunits are not), but are not found associated with the purified complex [197, 207]. Ycf4 in addition occurs in the WT in sub-stoichiometric amount compared with PSI subunits. Synthesis of the chloroplast encoded PSI subunits is not affected in the absence of either protein [197, 207], and their function in PSI biogenesis is still unknown. Mutation of ycf4 in Synechocystis does not completely prevent PSI assembly [198]. Rather than being true assembly catalysts, they could be involved in cofactor binding or in the biogenesis of a nucleus-encoded subunit, or play some other indirect role in assembly or stability. Similarly, the exact function of the $b t p A$ gene whose mutation in Synechocystis results in an 85\% decrease of PSI accumulation [199], remains to be elucidated. Another candidate assembly catalyst is the Arabidopsis Hcf136 factor, whose absence prevents accumulation of both the core PSII subunits and the OEEs [200].

\section{Repair versus ab initio assembly}

In the above, assembly of thylakoid membrane protein complexes is largely described in terms of successive steps, whereby the individual polypeptides are added sequentially to a 'nucleus' to form the final complex. Some of these intermediates can be observed with biochemical techniques, but most of them are only deduced from genetic or in vitro dissociation or reconstitution studies. Although this sequential view ('ab initio' assembly) may prove correct in many cases, especially during greening, assembly of a newly synthesized subunit can also proceed by direct integration into a preexisting complex.

As outlined above, a replacement mechanism has now been demonstrated for the D1 protein of PSII in mature chloroplasts, as was suggested early on by its higher turnover rate. Similarly, the three-times higher rate of synthesis of the $\alpha$ subunit of CF1 as compared to the $\beta$ subunit in Chlamydomonas [153] may indicate either that a large part of $\alpha$ is degraded in the early steps of assembly, or that the assembled $\mathrm{CF}_{1}$ undergoes cycles of degradation and replacement of $\alpha$. The latter explanation is supported by the finding that the ratio of labeling is similar in 5-min and 45-min pulses, and that it is also observed in the membrane-bound polypeptides after $5 \mathrm{~min}$ of labeling [147]. By analogy with PSII, the membrane-bound ATP synthase could shed its $\alpha$ subunits faster than its $\beta$, so that a large part of newly synthesized $\alpha$ would integrate directly in the ATP synthase. The complex regulation of the translational efficiencies of the atpA and atpB mRNAs would have evolved to maintain the levels of free $\alpha$ and $\beta$ to a minimum.

How can we identify cases of assembly by replacement? In practice, the fact that a newly synthesized polypeptide can rapidly integrate into a full-size complex in organello or when incubated with isolated thylakoids is a strong argument. The extrinsic subunits of PSI, when translated in vitro, can be imported into chloroplasts or insert into intact thylakoids, and they co-purify with the native complex $[122,201]$. Integration into thylakoids does not require ATP or stromal factors and purified PSI centers can also integrate PsaD [202]. The precursor form of PsaD assembles even better with PSI than the mature form, although removal of the transit peptide appears necessary for full integration [203]. In those experiments with tracer molecules, the intactness of the receptor membrane or isolated center is critical, otherwise one may just be witnessing in vitro reconstitution, as opposed to replacement. But the fact that membranes from a $p s a E$ mutant integrates only 2-3 times more PsaE than WT [122] suggests that PsaE replacement is a very efficient process in WT membranes.

Several studies using intact chloroplasts also speak in favor of a replacement mechanism. In a very elegant study, Shinohara et al. [169] showed that isolated pea chloroplasts could assemble a complete ATP synthase complex, even though the essential nucleus-encoded $\gamma, \delta$ and $\mathrm{CF}_{0}$-II subunits were not provided. In addition, upon import of labeled translation products from poly $(\mathrm{A})^{+}$ RNA, radioactive $\gamma, \delta$ and $\mathrm{CF}_{0}-\mathrm{II}$ were found in the $\mathrm{CF}_{0}-\mathrm{CF}_{1}$ fractions, indicating that assembly had proceeded to completion. No care was taken to inhibit chloroplast translation in the latter experiment, so the possibility remains that assembly had occurred with newly synthesized chloroplast polypeptides. However, this study also showed that isolated thylakoids could direct translation of $\alpha$ and $\beta$ and that they ended up in part in a full size ATP synthase complex. A possibility remains that pools of unassembled partner subunits were present or generated during the assay by dissociation of pre-existing complexes, as is also the case in other studies showing in organello assembly of $\beta$ into $\mathrm{CF}_{1}$ [204], or of the Rieske protein into cytochrome $b_{6} f[178]$. Clearly, the distinction between ab initio assembly and replacement can be made only in time-resolved studies, as demonstrated by van Wijk and collaborators. 


\section{Summary and conclusion}

Assembly of thylakoid membrane complexes is an extremely complex process whose mis-functioning could result in wasteful or even deleterious accumulation of incomplete, non-functional proteins in the membrane. This commands that assembly feeds back on the upstream and downstream processes, i.e., translation and degradation. Numerous mechanisms have evolved to permit efficient and properly timed delivery of assemblycompetent subunits. Developmental and light-regulated controls on transcription and translation insure that chlorophyll-proteins are produced only when pigments are available. The initiation of translation of certain subunits is controlled by the availability of their assembly partners which in turn depend on them for rapid stabilization. Membrane insertion of chloroplast-encoded intrinsic polypeptides occurs co-translationally, in some cases concomitantly with assembly. Failure to meet the proper assembly partner or cofactor usually results in rapid degradation of the non-assembled or misfolded subunits. However, incomplete complexes, sometimes of a relatively high stability, can accumulate in certain mutants, thus revealing probable intermediate steps of assembly. Not all subunits contribute equally to the stability of the complex. In particular, numerous small subunits with a single membrane span appear dispensable for assembly. In general, nucleus-encoded polypeptides are less essential to stability than the large core subunits synthesized in the chloroplast. Once fully assembled, a protein complex still can be subject to proteolysis, in some cases restricted to certain subunits of higher turnover rate. A vast array of proteases is probably involved in quality control and regulation at all stages of the biogenetic process.

\section{Acknowledgments}

We thank F.A. Wollman and all the members of the Wollman laboratory for sharing unpublished data and for stimulating discussion. Work in our laboratory is supported by CNRS (UPR1261).

\section{References}

[1] Wollman F.A., Minai L., Nechushtai R., The biogenesis and assembly of photosynthetic proteins in thylakoid membranes, Biochim. Biophys. Acta 1411 (1999) 21-85.

[2] Xia D., Yu C.A., Kim H., Xia J.Z., Kachurin A.M., Zhang L., Yu L., et al., Crystal structure of the cytochrome $b c_{1}$ complex from bovine heart mitochondria, Science 277 (1997) 60-66.

[3] Zhang Z., Huang L., Shulmeister V.M., Chi Y.I., Kim K.K., Hung L.W., Crofts A.R., et al., Electron transfer by domain movement in cytochrome $b c_{1}$, Nature 392 (1998) 677-684.

[4] Hurt E., Hauska G., a cytochrome $f / b_{6}$ complex of five polypeptides with plastoquinol-plastocyanin-oxidoreductase activity from spinach chloroplasts, Eur. J. Biochem. 117 (1981) 591-599.
[5] Pierre Y., Breyton C., Kramer D., Popot J.-L., Purification and characterisation of the cytochrome b6f complex of Chlamydomonas reinhardtii, J. Biol. Chem. 49 (1995) 29342-29349.

[6] Haley J., Bogorad L., A 4-kDa maize chloroplast polypeptide associated with the cytochrome $b_{6}-f$ complex: subunit 5 , encoded by the chloroplast petE gene, Proc. Natl. Acad. Sci. USA 86 (1989) 1534-1538.

[7] Takahashi Y., Rahire M., Breyton C., Popot J.-L., Joliot P., Rochaix J.-D., The chloroplast ycf7 (petL) open reading frame of Chlamydomonas reinhardtii encodes a small functionally important subunit of the cytochrome $b_{6} f$ complex, EMBO J. 15 (1996) 3498-3506.

[8] de Vitry C., Breyton C., Pierre Y., Popot J.L., The 4-kDa nuclear-encoded PetM polypeptide of the chloroplast cytochrome $b_{6} f$ complex. Nucleic acid and protein sequences, targeting signals, transmembrane topology, J. Biol. Chem. 271 (1996) 10667-10671.

[9] Hager M., Biehler K., Illerhaus J., Ruf S., Bock R., Targeted inactivation of the smallest plastid genome-encoded open reading frame reveals a novel and essential subunit of the cytochrome $b_{6} f$ complex, EMBO J. 18 (1999) 5834-5842.

[10] Breyton C., Tribet C., Olive J., Dubacq J.P., Popot J.L., Dimer to monomer conversion of the cytochrome $b_{6} f$ complex. Causes and consequences, J. Biol. Chem. 272 (1997) 21892-21900.

[11] Breyton C., de Vitry C., Popot J.L., Membrane association of cytochrome $b_{6} f$ subunits; the Rieske protein of Chlamydomonas reinhardtii is an extrinsic protein, J. Biol. Chem. 269 (1994) 7597-7602.

[12] Lemaire C., Girard-Bascou J., Wollman F.A., Bennoun P., Studies on the cytochrome $b_{6} f$ complex. I. Characterization of the complex subunits in Chlamydomonas reinhardtii, Biochim. Biophys. Acta 851 (1986) 229-238.

[13] Bruce B.D., Malkin R., Biosynthesis of the chloroplast cytochrome $b_{6} f$ complex: studies in a photosynthetic mutant of Lemna, Plant Cell 3 (1991) 203-212.

[14] Voelker R., Barkan A., Nuclear genes required for posttranslational steps in the biogenesis of the chloroplast cytochrome $b_{6} f$ complex in maize, Mol. Gen. Genet. 249 (1995) 507-514.

[15] Bendall D.S., Sanguansermsri M., Girard-Bascou J., Bennoun P., Mutations in Chlamydomonas reinhardtii affecting the cytochrome bf complex, FEBS Lett. 203 (1986) 31-35.

[16] Gumpel N.J., Ralley L., Girard-Bascou J., Wollman F.A., Nugent J.H., Purton S., Nuclear mutants of Chlamydomonas reinhardtii defective in the biogenesis of the cytochrome $b_{6} f$ complex, Plant Mol. Biol. 29 (1995) 921-932.

[17] Barkan A., Walker M., Nolasco M., Johnson D., A nuclear mutation in maize blocks the processing and translation of several chloroplast mRNAs and provides evidence for the differential translation of alternative mRNA forms, EMBO J. 13 (1994) 3170-3181.

[18] Wu X., Tsapin A., Shin Cho Y., Lee T.X., Metzger S., Genzlinger L., Holton B., et al., Reconstitution of the $2 \mathrm{Fe}-2 \mathrm{~S}$ center into overproduced Rieske protein and mutational analysis of inhibitor specificity in cytochrome $b_{6}$ in cyanobacteria, in: Mathis P. (Ed.), Photosynthesis: from light to biosphere, Kluwer Academic Publishers, Dordrecht, 1995, pp. 769-772.

[19] Kalsbeck W.A., Robertson D.E., Pandey R.K., Smith K.M., Dutton P.L., Bocian D.F., Structural and electronic properties of the heme cofactors in a multi-heme synthetic cytochrome, Biochemistry 35 (1996) 3429-3438.

[20] Kuras R., de Vitry C., Choquet Y., Girard-Bascou J., Culler D., Buschlen S., Merchant S., et al., Molecular genetic identification of a pathway for heme binding to cytochrome $b_{6}$, J. Biol. Chem. 272 (1997) 32427-32435.

[21] Pierre Y., Breyton C., Lemoine Y., Robert B., Vernotte C., Popot J.L., On the presence and role of a molecule of chlorophyll a in the cytochrome $b_{6} f$ complex, J. Biol. Chem. 272 (1997) 21901-21908. 
[22] Zhang H., Huang D., Cramer W.A., Stoichiometrically bound beta-carotene in the cytochrome $b_{6} f$ complex of oxygenic photosynthesis protects against oxygen damage, J. Biol. Chem. 274 (1999) 1581-1587.

[23] De Heij H.T., Jochemsen A.G., Willemsen P.T., Groot G.S., Protein synthesis during chloroplast development in Spirodela oligorhiza. Coordinated synthesis of chloroplast-encoded and nuclear- encoded subunits of ATPase and ribulose-1, 5-bisphosphate carboxylase, Eur. J. Biochem. 138 (1984) 161-168.

[24] Kuras R., Wollman F.A., The assembly of cytochrome $b_{6} f$ complexes: an approach using genetic transformation of the green alga Chlamydomonas reinhardtii, EMBO J. 13 (1994) 1019-1027.

[25] Monde R.A., Zito F., Olive J., Wollman F.A., Stern D.B., Post-translational defects in tobacco chloroplast mutants lacking the cytochrome $b_{6} f$ complex, Plant J. 21 (2000) 61-72.

[26] Berthold D.A., Schmidt C.L., Malkin R., The deletion of petG in Chlamydomonas reinhardtii disrupts the cytochrome bf complex, J. Biol. Chem. 270 (1995) 29293-29298.

[27] Finazzi G., Buschlen S., de Vitry C., Rappaport F., Joliot P., Wollman F.-A., Function-directed mutagenesis of the cytochrome $b_{6} f$ complex in Chlamydomonas reinhardtii: involvement of the cd loop of cytochrome $b_{6}$ in quinol binding to the Qo site, Biochemistry 39 (1997) 2867-2874.

[28] de Vitry C., Finazzi G., Baymann F., Kallas T., Analysis of the nucleus-encoded and chloroplast-targeted rieske protein by classic and site-directed mutagenesis of Chlamydomonas, Plant Cell 11 (1999) 2031-2044.

[29] Valkova-Valchanova M.B., Saribas A.S., Gibney B.R., Dutton P.L., Daldal F., Isolation and characterization of a two-subunit cytochrome $b-c_{1}$ subcomplex from Rhodobacter capsulatus and reconstitution of its ubihydroquinone oxidation $\left(\mathrm{Q}_{\mathrm{o}}\right)$ site with purified $\mathrm{Fe}-\mathrm{S}$ protein subunit, Biochemistry 37 (1998) 16242-16251.

[30] Majeran W., Wollman F.A., Vallon O., Evidence for a role of $\mathrm{ClpP}$ in the degradation of the chloroplast cytochrome $b_{6} f$ complex, Plant Cell 12 (2000) 137-150.

[31] Ostersetzer O., Adam Z., Light-stimulated degradation of an unassembled Rieske FeS protein by a thylakoid-bound protease: the possible role of the FtsH protease, Plant Cell 9 (1997) 957-965.

[32] Wollman F.A., Kuras R., Choquet Y., Epistatic effects in thylakoid protein synthesis: the example of cytochrome $f$, in: Mathis P. (Ed.), Photosynthesis: from light to biosphere, Kluwer Academic Publishers, Dordrecht, 1995, pp. 737-742.

[33] Choquet Y., Stern D.B., Wostrikoff K., Kuras R., Girard-Bascou J., Wollman F.A., Translation of cytochrome $\mathrm{f}$ is autoregulated through the 5'untranslated region of petA mRNA in Chlamydomonas chloroplasts, Proc. Natl. Acad. Sci. USA 95 (1998) 4380-4385.

[34] Kuras R., Wollman F.A., Joliot P., Conversion of cytochrome $f$ to a soluble form in vivo in Chlamydomonas reinhardtii, Biochemistry 34 (1995) 7468-7475.

[35] Girard-Bascou J., Choquet Y., Gumpel N.J., Culler D., Purton S., Merchant S., Laquerriere F.E., et al., Nuclear control of the expression of the chloroplast pet genes in Chlamydomonas reinhardtii, in: Mathis P. (Ed.), Photosynthesis: from light to biosphere, Kluwer Academic Publishers, Dordrecht, 1995, pp. 683-686.

[36] Fisk D.G., Walker M.B., Barkan A., Molecular cloning of the maize gene $c r p 1$ reveals similarity between regulators of mitochondrial and chloroplast gene expression, EMBO J. 18 (1999) 2621-2630.

[37] Kuras R., Guergova-Kuras M., Crofts A.R., Steps toward constructing a cytochrome $b_{6} \mathrm{f}$ complex in the purple bacterium Rhodobacter sphaeroides: an example of the structural plasticity of a membrane cytochrome, Biochemistry 37 (1998) 16280-16288.
[38] Saribas A.S., Mandaci S., Daldal F., An engineered cytochrome $b_{6} c_{1}$ complex with a split cytochrome $b$ is able to support photosynthetic growth of Rhodobacter capsulatus, J. Bacteriol. 181 (1999) 5365-5372.

[39] Zheleva D., Sharma J., Panico M., Morris H.R., Barber J., Isolation and characterization of monomeric and dimeric CP47reaction center photosystem II complexes, J. Biol. Chem. 273 (1998) 16122-16127.

[40] Boekema E.J., Van Roon H., Calkoen F., Bassi R., Dekker J.P., Multiple types of association of photosystem II and its lightharvesting antenna in partially solubilized photosystem II membranes, Biochemistry 38 (1999) 2233-2239.

[41] Hankamer B., Barber J., Boekema E.J., Structure and membrane organization of Photosystem II in green plants, Annu. Rev. Plant Physiol. Mol. Biol. 48 (1997) 641-671.

[42] Funk C., Adamska I., Green B.R., Andersson B., Renger G., The nuclear-encoded chlorophyll-binding photosystem II-S protein is stable in the absence of pigments, J. Biol. Chem. 270 (1995) 30141-30147.

[43] Lorkovic Z.J., Schroder W.P., Pakrasi H.B., Irrgang K.D., Herrmann R.G., Oelmuller R., Molecular characterization of PsbW, a nuclear-encoded component of the photosystem II reaction center complex in spinach, Proc. Natl. Acad. Sci. USA 92 (1995) 8930-8934.

[44] Malnoe P., Mayfield S.P., Rochaix J.D., Comparative analysis of the biogenesis of photosystem II in the wild- type and Y-1 mutant of Chlamydomonas reinhardtii, J. Cell Biol. 106 (1988) 609-616.

[45] Edhofer I., Muhlbauer S.K., Eichacker L.A., Light regulates the rate of translation elongation of chloroplast reaction center protein D1, Eur. J. Biochem. 257 (1998) 78-84.

[46] Eichacker L.A., Soll J., Lauterbach P., Rudiger W., Klein R.R., Mullet J.E., In vitro synthesis of chlorophyll a in the dark triggers accumulation of chlorophyll $a$ apoproteins in barley etioplasts, J. Biol. Chem. 265 (1990) 13566-13571.

[47] Kim J., Eichacker L.A., Rudiger W., Mullet J.E., Chlorophyll regulates accumulation of the plastid-encoded chlorophyll proteins P700 and D1 by increasing apoprotein stability, Plant Physiol. 104 (1994) 907-916.

[48] Muller B., Eichacker L.A., Assembly of the D1 precursor in monomeric photosystem II reaction center precomplexes precedes chlorophyll $a$-triggered accumulation of reaction center II in barley etioplasts, Plant Cell 11 (1999) 2365-2378.

[49] Erickson J.M., Assembly of Photosystem II, in: Rochaix J.-D., Goldschmidt-Clermont M., Merchant S. (Eds.), The molecular biology of chloroplasts and mitochondria in Chlamydomonas, Kluwer Academic Publishers, Dordrecht, 1998, pp. 225-285.

[50] de Vitry C., Olive J., Drapier D., Recouvreur M., Wollman F.A., Posttranslational events leading to the assembly of photosystem II protein complex: a study using photosynthesis mutants from Chlamydomonas reinhardtii, J. Cell Biol. 109 (1989) 991-1006.

[51] Morais F., Barber J., Nixon P.J., The chloroplast-encoded alpha subunit of cytochrome b-559 is required for assembly of the photosystem two complex in both the light and the dark in Chlamydomonas reinhardtii, J. Biol. Chem. 273 (1998) 29315-29320.

[52] Simpson D.J., Vallon O., Von Wettstein D., Freeze-fracture studies on barley plastid membranes. VIII: In viridis- ${ }^{115}$, a mutant completley lacking Photosystem II, oxygen evolution enhancer 1 (OEE1) and $\alpha$-subunit of cytochrome $b$-559 accumulate in appressed thylakoids, Biochim. Biophys. Acta 975 (1989) $164-174$.

[53] Gamble P.E., Mullet J.E., Translation and stability of proteins encoded by the plastid $p s b A$ and $p s b B$ genes are regulated by a nuclear gene during light-induced chloroplast development in barley, J. Biol. Chem. 264 (1989) 7236-7243.

[54] Nilsson F., Andersson B., Jansson C., Photosystem II characteristics of a constructed Synechocystis 6803 mutant lacking synthesis of the D1 polypeptide, Plant Mol. Biol. 14 (1990) 1051-1054. 
[55] Pakrasi H.B., de Ciechi P., Whitmarsh J., Site directed mutagenesis of the heme axial ligands of cytochrome $b_{559}$ affects the stability of the photosystem II complex, EMBO J. 10 (1991) 1619-1627.

[56] Hashimoto A., Akasaka T., Yamamoto Y., Characteristics of the assembly of the $33 \mathrm{kDa}$ oxygen-evolving complex protein in the etioplasts and the developping chloroplasts of barley seedlings, Biochim. Biophys. Acta 1183 (1996) 397-407.

[57] Bricker T.M., Ghanotakis D.F., Introduction to oxygen evolution and the oxygen-evolving complex, in: Ort D.R., Yocum C.F. (Eds.), Oxygenic Photosynthesis: The Light Reactions. Series Advances in Photosynthesis, Kluwer Academic Publishers, Dordrecht, 1996, pp. 113-136.

[58] Eisenberg-Domovich Y., Oelmuller R., Herrmann R.G., Ohad I., Role of the RCII-D1 protein in the reversible association of the oxygen- evolving complex proteins with the lumenal side of photosystem II, J. Biol. Chem. 270 (1995) 30181-30186.

[59] Hashimoto A., Yamamoto Y., Theg S.M., Unassembled subunits of the photosynthetic oxygen-evolving complex present in the thylakoid lumen are long-lived and assembly-competent, FEBS Lett. 391 (1996) 29-34.

[60] Kuwabara T., Suzuki K., A prolyl endoproteinase that acts specifically on the extrinsic $18-\mathrm{kDa}$ protein of photosystem II: purification and further characterization, Plant Cell Physiol. 35 (1994) 665-675.

[61] Monod C., Takahashi Y., Goldschmidt-Clermont M., Rochaix J.D., The chloroplast $y c f 8$ open reading frame encodes a photosystem II polypeptide which maintains photosynthetic activity under adverse growth conditions, EMBO J. 13 (1994) 2747-2754.

[62] Shen J.R., Ikeuchi M., Inoue Y., Analysis of the $p s b U$ gene encoding the $12-\mathrm{kDa}$ extrinsic protein of photosystem II and studies on its role by deletion mutagenesis in Synechocystis sp. PCC 6803, J. Biol. Chem. 272 (1997) 17821-17826.

[63] Ikeuchi M., Shukla V.K., Pakrasi H.B., Inoue Y., Directed inactivation of the psbI gene does not affect photosystem II in the cyanobacterium Synechocystis sp. PCC 6803, Mol. Gen. Genet. 249 (1995) 622-628.

[64] Kunstner P., Guardiola A., Takahashi Y., Rochaix J.D., A mutant strain of Chlamydomonas reinhardtii lacking the chloroplast photosystem II PsbI gene grows photoautotrophically, J. Biol. Chem. 270 (1995) 9651-9654.

[65] Anbudurai P.R., Pakrasi H.B., Mutational analysis of the PsbL protein of photosystem II in the cyanobacterium Synechocystis sp. PCC 6803, Z. Naturforsch. 48 (1993) 267-274.

[66] Kitamura K., Ozawa S., Shiina T., Toyoshima Y., L protein, encoded by psbL, restores normal functioning of the primary quinone acceptor, $\mathrm{Q}_{\mathrm{A}}$, in isolated D1/D2/CP47/Cytb-559/I photosystem II reaction center core complex, FEBS Lett. 354 (1994) $113-116$.

[67] Summer E.J., Schmid V.H., Bruns B.U., Schmidt G.W., Requirement for the $\mathrm{H}$ phosphoprotein in photosystem II of Chlamydomonas reinhardtii, Plant Physiol. 113 (1997) 1359-1368.

[68] Takahashi Y., Matsumoto H., Goldschmidt-Clermont M., Rochaix J.D., Directed disruption of the Chlamydomonas chloroplast $p s b K$ gene destabilizes the photosystem II reaction center complex, Plant Mol. Biol. 24 (1994) 779-788.

[69] Mayers S.R., Dubbs J.M., Vass I., Hideg E., Nagy L., Barber J., Further characterization of the psbH locus of Synechocystis sp. PCC 6803: inactivation of $p s b H$ impairs $\mathrm{Q}_{\mathrm{A}}$ to $\mathrm{Q}_{\mathrm{B}}$ electron transport in photosystem 2, Biochemistry 32 (1993) 1454-1465.

[70] Ikeuchi M., Eggers B., Shen G.Z., Webber A., Yu J.J., Hirano A., Inoue Y., et al., Cloning of the psbK gene from Synechocystis sp. PCC 6803 and characterization of photosystem II in mutants lacking PSII-K, J. Biol. Chem. 266 (1991) 11111-11115.

[71] Vermaas W.F.J., Ikeuchi M., Inoue Y., Protein composition of the photosystem II core complex in genetically engineered mutants of the cyanobacterium Synechocystis sp. PCC 6803, Photosynth. Res. 17 (1988) 97-113.
[72] Kyle D.J., Ohad I., Arntzen C.J., Membrane protein damage and repair: Selective loss of a quinone-protein function in chloroplast membranes, Proc. Natl. Acad. Sci. USA 81 (1984) 4070-4074.

[73] Ohad I., Keren N., Zer H., Gong H., Mor T.S., Gal A., Tal S., et al., Light-induced degradation of the photosystem II reaction centre D1 protein in vivo: an integrative approach, in: Baker N. (Ed.), Photoinhibition from the molecule to the field, Bios Scientific Publishers, Oxford, UK, 1994, pp. 161-177.

[74] Mor T.S., Hundal T., Ohad I., Andersson B., The fate of cytochrome $b_{559}$ during anaerobic photoinhibition and its recovery process, Photosynth. Res. 53 (1997) 205-213.

[75] Barbato R., Friso G., Rigoni F., Vecchia F.D., Giacometti G.M., Structural changes and lateral redistribution of photosystem II during donor side photoinhibition of thylakoids, J. Cell Biol. 119 (1992) 325-335.

[76] Aro E.M., Virgin I., Andersson B., Photoinhibition of Photosystem II. Inactivation, protein damage and turnover, Biochim. Biophys. Acta 1143 (1993) 113-134.

[77] Hagman A., Shi L.X., Rintamaki E., Andersson B., Schroder W.P., The nuclear-encoded PsbW protein subunit of photosystem II undergoes light-induced proteolysis, Biochemistry 36 (1997) 12666-12671.

[78] Kruse O., Zheleva D., Barber J., Stabilization of photosystem two dimers by phosphorylation: implication for the regulation of the turnover of D1 protein, FEBS Lett. 408 (1997) 276-280.

[79] Rintamaki E., Kettunen R., Aro E.M., Differential D1 dephosphorylation in functional and photodamaged photosystem II centers. Dephosphorylation is a prerequisite for degradation of damaged D1, J. Biol. Chem. 271 (1996) 14870-14875.

[80] de Vitry C., Diner B.A., Popot J.L., Photosystem II particles from Chlamydomonas reinhardtii. Purification, molecular weight, small subunit composition, and protein phosphorylation, J. Biol. Chem. 266 (1991) 16614-16621.

[81] Pursiheimo S., Rintamaki E., Baena-Gonzalez E., Aro E.M., Thylakoid protein phosphorylation in evolutionally divergent species with oxygenic photosynthesis, FEBS Lett. 423 (1998) 178-182.

[82] De Las Rivas J., Andersson B., Barber J., Two sites of primary degradation of the D1-protein induced by acceptor or donor side photo-inhibition in photosystem II core complexes, FEBS Lett. 301 (1992) 246-252.

[83] Shipton C.A., Barber J., In vivo and in vitro photoinhibition reactions generate similar degradation fragments of D1 and D2 photosystem-II reaction-centre proteins, Eur. J. Biochem. 220 (1994) 801-808.

[84] Shipton C.A., Barber J., Photoinduced degradation of the D1 polypeptide in isolated reaction centers of photosystem II: evidence for an autoproteolytic process triggered by the oxidizing side of the photosystem, Proc. Natl. Acad. Sci. USA 88 (1991) 6691-6695.

[85] Spetea C., Hundal T., Lohmann F., Andersson B., GTP bound to chloroplast thylakoid membranes is required for light- induced, multienzyme degradation of the photosystem II D1 protein, Proc. Natl. Acad. Sci. USA 96 (1999) 6547-6552.

[86] Clarke A.K., Schelin J., Porankiewicz J., Inactivation of the clpP1 gene for the proteolytic subunit of the ATP- dependent Clp protease in the cyanobacterium Synechococcus limits growth and light acclimation, Plant Mol. Biol. 37 (1998) 791-801.

[87] Porankiewicz J., Schelin J., Clarke A.K., The ATP-dependent Clp protease is essential for acclimation to UV-B and low temperature in the cyanobacterium Synechococcus, Mol. Microbiol. 29 (1998) 275-283.

[88] Barbato R., Frizzo A., Friso G., Rigoni F., Giacometti G.M., Degradation of the D1 protein of photosystem-II reaction centre by ultraviolet-B radiation requires the presence of functional manganese on the donor side, Eur. J. Biochem. 227 (1995) 723-729. 
[89] Hundal T., Virgin I., Styring S., Andersson B., Changes in the organization of photosystem II following light-induced D1protein degradation, Biochim. Biophys. Acta 1017 (1990) 235-241.

[90] Schuster G., Timberg R., Ohad I., Turnover of thylakoid photosystem II proteins during photoinhibition of Chlamydomonas reinhardtii, Eur. J. Biochem. 177 (1988) 403-410.

[91] Zer H., Ohad I., Photoinactivation of photosystem II induces changes in the photochemical reaction center II abolishing the regulatory role of the $\mathrm{Q}_{\mathrm{B}}$ site in the $\mathrm{D} 1$ protein degradation, Eur. J. Biochem. 231 (1995) 448-453.

[92] Schroda M., Vallon O., Wollman F.A., Beck C.F., A chloroplasttargeted heat shock protein 70 (HSP70) contributes to the photoprotection and repair of photosystem II during and after photoinhibition, Plant Cell 11 (1999) 1165-1178.

[93] Ortega J.M., Roncel M., Losada M., Light-induced degradation of cytochrome $b_{559}$ during photoinhibition of the photosystem II reaction center, FEBS Lett. 458 (1999) 87-92.

[94] Ishikawa Y., Nakatani E., Henmi T., Ferjani A., Harada Y., Tamura N., Yamamoto Y., Turnover of the aggregates and cross-linked products of the D1 protein generated by acceptorside photoinhibition of photosystem II, Biochim. Biophys. Acta 1413 (1999) 147-158.

[95] Kettunen R., Pursiheimo S., Rintamaki E., Van Wijk K.J., Aro E.M., Transcriptional and translational adjustments of psbA gene expression in mature chloroplasts during photoinhibition and subsequent repair of photosystem II, Eur. J. Biochem. 247 (1997) 441-448.

[96] Zer H., Prasil O., Ohad I., Role of plastoquinol oxidoreduction in regulation of photochemical reaction center II D1 protein turnover in vivo, J. Biol. Chem. 269 (1994) 17670-17676.

[97] Mattoo A.K., Edelman M., Intramembrane translocation and posttranslational palmitoylation of the chloroplast $32-\mathrm{kDa}$ herbicide-binding protein, Proc. Natl. Acad. Sci. USA 84 (1987) 1497-1501.

[98] Klein R.R., Mason H.S., Mullet J.E., Light-regulated translation of chloroplast proteins. I. Transcripts of psaA-psaB, psbA, and $r b c L$ are associated with polysomes in dark-grown and illuminated barley seedlings, J. Cell Biol. 106 (1988) 289-301.

[99] Muhlbauer S.K., Eichacker L.A., Light-dependent formation of the photosynthetic proton gradient regulates translation elongation in chloroplasts, J. Biol. Chem. 273 (1998) 20935-20940.

[100] Anbudurai P.R., Mor T.S., Ohad I., Shestakov S.V., Pakrasi H.B., The $c t p A$ gene encodes the C-terminal processing protease for the D1 protein of the photosystem II reaction center complex, Proc. Natl. Acad. Sci. USA 91 (1994) 8082-8086.

[101] Kim J., Klein P.G., Mullet J.E., Ribosomes pause at specific sites during synthesis of membrane-bound chloroplast reaction center protein D1, J. Biol. Chem. 266 (1991) 14931-14938.

[102] Kim J., Klein P.G., Mullet J.E., Synthesis and turnover of photosystem II reaction center protein D1. Ribosome pausing increases during chloroplast development, J. Biol. Chem. 269 (1994) 17918-17923.

[103] Mullet J.E., Klein P.G., Klein R.R., Chlorophyll regulates accumulation of the plastid-encoded chlorophyll apoproteins CP43 and D1 by increasing apoprotein stability, Proc. Natl. Acad. Sci. USA 87 (1990) 4038-4042.

[104] Eichacker L.A., Helfrich M., Rudiger W., Muller B., Stabilization of chlorophyll $a$-binding apoproteins P700, CP47, CP43, D2, and D1 by chlorophyll a or Zn-pheophytin $a$, J. Biol. Chem. 271 (1996) 32174-32179.

[105] Adir N., Shochat S., Ohad I., Light-dependent D1 protein synthesis and translocation is regulated by reaction center II. Reaction center II serves as an acceptor for the D1 precursor, J. Biol. Chem. 265 (1990) 12563-12568.

[106] Van Wijk K.J., Andersson B., Aro E.M., Kinetic resolution of the incorporation of the D1 protein into photosystem II and localization of assembly intermediates in thylakoid membranes of spinach chloroplasts, J. Biol. Chem. 271 (1996) 9627-9636.
[107] Zhang L., Paakkarinen V., van Wijk K.J., Aro E.M., Cotranslational assembly of the D1 protein into photosystem II, J. Biol. Chem. 274 (1999) 16062-16067.

[108] Van Wijk K.J., Roobol-Boza M., Kettunen R., Andersson B., Aro E.M., Synthesis and assembly of the D1 protein into photosystem II: processing of the C-terminus and identification of the initial assembly partners and complexes during photosystem II repair, Biochemistry 36 (1997) 6178-6186.

[109] Kim J., Klein P.G., Mullet J.E., Vir-115 gene product is required to stabilize D1 translation intermediates in chloroplasts, Plant Mol. Biol. 25 (1994) 459-467.

[110] Nechushtai R., Eden A., Cohen Y., Klein J., Introduction to Photosystem I: Reaction Center Function, Composition and Structure, in: Ort D.R., Yocum C.F. (Eds.), Oxygenic Photosynthesis: The Light Reactions. Series Advances in Photosynthesis, Kluwer Academic Publishers, Dordrecht, 1995, pp. 289-311.

[111] Rodermel S.R., Bogorad L., Molecular evolution and nucleotide sequences of the maize plastid genes for the alpha subunit of $\mathrm{CF}_{1}$ (atpA) and the proteolipid subunit of $\mathrm{CF}_{0}(a t p H)$, Genetics 116 (1987) 127-139.

[112] Nitschke W., Rutherford A.W., Photosynthetic reaction centres: variations on a common structural theme? Trends Biochem. Sci. 16 (1991) 241-245.

[113] Soukoulis V., Savikhin S., Xu W., Chitnis P.R., Struve W.S., Electronic spectra of PS I mutants: the peripheral subunits do not bind red chlorophylls in Synechocystis sp. PCC 6803, Biophys. J. 76 (1999) 2711-2715.

[114] Mullet J.E., Burke J.J., Arntzen C.J., Chlorophyll proteins of photosystem I, Plant Physiol. 65 (1980) 814-822.

[115] Bengis C., Nelson N., Subunit structure of chloroplast photosystem I reaction center, J. Biol. Chem. 252 (1977) 4564-4568.

[116] Li N., Warren P.V., Golbeck J.H., Frank G., Zuber H., Bryant D.A., Polypeptide composition of the Photosystem I complex and the Photosystem I core protein from Synechococcus sp. PCC 6301, Biochim. Biophys. Acta 1059 (1991) 215-225.

[117] Naver H., Scott M.P., Golbeck J.H., Olsen C.E., Scheller H.V., The eight-amino acid internal loop of PSI-C mediates association of low molecular mass iron-sulfur proteins with the $\mathrm{P} 700-\mathrm{F}_{\mathrm{X}}$ core in photosystem I, J. Biol. Chem. 273 (1998) 18778-18783.

[118] Zhao J.D., Warren P.V., Li N., Bryant D.A., Golbeck J.H., Reconstitution of electron transport in photosystem I with PsaC and PsaD proteins expressed in Escherichia coli, FEBS Lett. 276 (1990) 175-180.

[119] Jin P., Sun J., Chitnis P.R., Structural features and assembly of the soluble overexpressed PsaD subunit of photosystem I, Biochim. Biophys. Acta 1410 (1999) 7-18.

[120] Yu J., Smart L.B., Jung Y.S., Golbeck J., Mc Intosh L., Absence of PsaC subunit allows assembly of photosystem I core but prevents the binding of PsaD and PsaE in Synechocystis sp. PCC6803, Plant Mol. Biol. 29 (1995) 331-342.

[121] Li N., Zhao J.D., Warren P.V., Warden J.T., Bryant D.A., Golbeck J.H., PsaD is required for the stable binding of PsaC to the photosystem I core protein of Synechococcus sp. PCC 6301, Biochemistry 30 (1991) 7863-7872.

[122] Chitnis P.R., Nelson N., Assembly of 2 subunits of the cyanobacterial photosystem I on the $\mathrm{N}$-side of thylakoid membranes, Plant Physiol. 99 (1992) 239-246.

[123] Xu Q., Jung Y.S., Chitnis V.P., Guikema J.A., Golbeck J.H., Chitnis P.R., Mutational analysis of photosystem I polypeptides in Synechocystis sp. PCC 6803. Subunit requirements for reduction of $\mathrm{NADP}^{+}$mediated by ferredoxin and flavodoxin, J. Biol. Chem. 269 (1994) 21512-21518.

[124] Yu L., Zhao J.D., Muhlenhoff U., Bryant D.A., Golbeck J.H., PsaE is required for in vivo cyclic electron flow around Photosystem I in the cyanobacterium Synechococcus sp. PCC7002, Plant Physiol. 103 (1993) 171-180.

[125] Chitnis P.R., Purvis D., Nelson N., Molecular cloning and targeted mutagenesis of the gene $p s a F$ encoding subunit III of photosystem I from the cyanobacterium Synechocystis sp. PCC 6803, J. Biol. Chem. 266 (1991) 20146-20151. 
[126] Chitnis V.P., Chitnis P.R., PsaL subunit is required for the formation of photosystem I trimers in the cyanobacterium Synechocystis sp. PCC 6803, FEBS Lett. 336 (1993) 330-334.

[127] Xu Q., Armbrust T.S., Guikema J.A., Chitnis P.R., Organization of photosystem I polypeptides. a structural interaction between the psaD and psaL subunits, Plant Physiol. 106 (1994) 1057-1063.

[128] Xu Q., Hoppe D., Chitnis V.P., Odom W.R., Guikema J.A., Chitnis P.R., Mutational analysis of photosystem I polypeptides in the cyanobacterium Synechocystis sp. PCC 6803. Targeted inactivation of psaI reveals the function of PsaI in the structural organization of PsaL, J. Biol. Chem. 270 (1995) 16243-16250.

[129] Xu Q., Yu L., Chitnis V.P., Chitnis P.R., Function and organization of photosystem I in a cyanobacterial mutant strain that lacks PsaF and PsaJ subunits, J. Biol. Chem. 269 (1994) 3205-3211.

[130] Chitnis P.R., Reilly P.A., Nelson N., Insertional inactivation of the gene encoding subunit II of photosystem I from the cyanobacterium Synechocystis sp. PCC 6803, J. Biol. Chem. 264 (1989) 18381-18385.

[131] Smart L.B., Anderson S.L., Mc Intosh L., Targeted genetic inactivation of the photosystem I reaction center in the cyanobacterium Synechocystis sp. PCC 6803, EMBO J. 10 (1991) 3289-3296.

[132] Smart L.B., McIntosh L., Genetic inactivation of the $p s a B$ gene in Synechocystis sp. PCC 6803 disrupts assembly of photosystem I, Plant Mol. Biol. 21 (1993) 177-180.

[133] Girard-Bascou J., Choquet Y., Schneider M., Delosme M., Dron M., Characterization of a chloroplast mutation in the psaA2 gene of Chlamydomonas reinhardtii, Curr. Genet. 12 (1987) 489-495.

[134] Redding K., Macmillan F., Leibl W., Brettel K., Hanley J., Rutherford A.W., Breton J., et al., A systematic survey of conserved histidines in the core subunits of Photosystem I by site-directed mutagenesis reveals the likely axial ligands of P700, EMBO J. 17 (1998) 50-60.

[135] Webber A.N., Gibbs P.B., Ward J.B., Bingham S.E., Site-directed mutagenesis of the photosystem I reaction center in chloroplasts - the proline-cysteine motif, J. Biol. Chem. 268 (1993) 12990-12995.

[136] Takahashi Y., Goldschmidt-Clermont M., Soen S.Y., Franzen L.G., Rochaix J.D., Directed chloroplast transformation in Chlamydomonas reinhardtii: insertional inactivation of the $p s a C$ gene encoding the iron sulfur protein destabilizes photosystem I, EMBO J. 10 (1991) 2033-2040.

[137] Farah J., Rappaport F., Choquet Y., Joliot P., Rochaix J.D., Isolation of a psaF-deficient mutant of Chlamydomonas reinhardtii: efficient interaction of plastocyanin with the photosystem I reaction center is mediated by the PsaF subunit, EMBO J. 14 (1995) 4976-4984.

[138] Fischer N., Boudreau E., Hippler M., Drepper F., Haehnel W., Rochaix J.D., A large fraction of $\mathrm{PsaF}$ is nonfunctional in photosystem I complexes lacking the PsaJ subunit, Biochemistry 38 (1999) 5546-5552.

[139] Boyer P.D., The ATP synthase--a splendid molecular machine, Annu. Rev. Biochem. 66 (1997) 717-749.

[140] Pick U., Racker E., Purification and reconstitution of the N, N'-dicyclohexylcarbodiimide- sensitive ATPase complex from spinach chloroplasts, J. Biol. Chem. 254 (1979) 2793-2799.

[141] Younis H.M., Winget G.D., Racker E., Requirement of the delta subunit of chloroplast coupling factor 1 for photophosphorylation, J. Biol. Chem. 252 (1977) 1814-1818.

[142] Abrahams J.P., Leslie A.G., Lutter R., Walker J.E., Structure at $2.8 \AA$ resolution of $\mathrm{F}_{1}$-ATPase from bovine heart mitochondria, Nature 370 (1994) 621-628.

[143] Stock D., Leslie A.G., Walker J.E., Molecular architecture of the rotary motor in ATP synthase, Science 286 (1999) 1700-1705.

[144] Chen G.G., Jagendorf A.T., Chloroplast molecular chaperoneassisted refolding and reconstitution of an active multisubunit coupling factor $\mathrm{CF}_{1}$ core, Proc. Natl. Acad. Sci. USA 91 (1994) 11497-11501.
[145] Gao F., Lipscomb B., Wu I., Richter M.L., In vitro assembly of the core catalytic complex of the chloroplast ATP synthase, J. Biol. Chem. 270 (1995) 9763-9769.

[146] Engelbrecht S., Junge W., Added subunit $\beta$ of CF1 as well as $\gamma / \delta / \varepsilon$ restore photophosphorylation in partly $\mathrm{CF}_{1}$-depleted thylakoids, Biochim. Biophys. Acta 1140 (1992) 157-162.

[147] Lemaire C., Wollman F.A., The chloroplast ATP synthase in Chlamydomonas reinhardtii. II. Biochemical studies on its biogenesis using mutants defective in photophosphorylation, J. Biol. Chem. 264 (1989) 10235-10242.

[148] Piccioni R.G., Bennoun P., Chua N.H., A nuclear mutant of Chlamydomonas reinhardtii defective in photosynthetic photophosphorylation. Characterization of the algal coupling factor ATPase, Eur. J. Biochem. 117 (1981) 93-102.

[149] Fiedler H.R., Schmid R., Leu S., Shavit N., Strotmann H., Isolation of $\mathrm{CF}_{0} \mathrm{CF}_{1}$ from Chlamydomonas reinhardtii $\mathrm{cw} 15$ and the $\mathrm{N}$ - terminal amino acid sequences of the $\mathrm{CF}_{0} \mathrm{CF}_{1}$ subunits, FEBS Lett. 377 (1995) 163-166.

[150] Lemaire C., Wollman F.A., The chloroplast ATP synthase in Chlamydomonas reinhardtii. I. Characterization of its nine constitutive subunits, J. Biol. Chem. 264 (1989) 10228-10234.

[151] Smart E.J., Selman B.R., Complementation of a Chlamydomonas reinhardtii mutant defective in the nuclear gene encoding the chloroplast coupling factor $1\left(\mathrm{CF}_{1}\right)$ gamma-subunit (atpC), J. Bioenerg. Biomembr. 25 (1993) 275-284.

[152] Robertson D., Boynton J.E., Gillham N.W., Cotranscription of the wild-type chloroplast atpE gene encoding the $\mathrm{CF}_{1} / \mathrm{CF}_{0}$ epsilon subunit with the 3'half of the rps7 gene in Chlamydomonas reinhardtii and characterization of frameshift mutations in atpE, Mol. Gen. Genet. 221 (1990) 155-163.

[153] Drapier D., Girard-Bascou J., Wollman F.-A., Evidence for nuclear control of the expression of the atpA and atpB chloroplast genes in Chlamydomonas, Plant Cell 4 (1992) 283-295.

[154] Ketchner S.L., Drapier D., Olive J., Gaudriault S., GirardBascou J., Wollman F.A., Chloroplasts can accommodate inclusion bodies. Evidence from a mutant of Chlamydomonas reinhardtii defective in the assembly of the chloroplast ATP synthase, J. Biol. Chem. 270 (1995) 15299-15306.

[155] Steinemann D., Engelbrecht S., Lill H., Reassembly of Synechocystis sp. PCC $6803 \mathrm{~F}_{1}$-ATPase from its over-expressed subunits, FEBS Lett. 362 (1995) 171-174.

[156] Du Z., Gromet-Elhanan Z., Refolding of recombinant alpha and beta subunits of the Rhodospirillum rubrum $\mathrm{F}_{\mathrm{o}} \mathrm{F}_{1}$ ATP synthase into functional monomers that reconstitute an active alpha(1) beta(1)-dimer, Eur. J. Biochem. 263 (1999) 430-437.

[157] Stampacchia O., Girard-Bascou J., Zanasco J.L., Zerges W., Bennoun P., Rochaix J.D., A nuclear-encoded function essential for translation of the chloroplast psaB mRNA in Chlamydomonas, Plant Cell 9 (1997) 773-782.

[158] Bennoun P., Spierer-Herz M., Erickson J., Girard-Bascou J., Pierre Y., Delosme M., Rochaix J.D., Characterization of photosystem II mutants of Chlamydomonas reinhardii lacking the $p s b A$ gene, Plant Mol. Biol. 6 (1986) 151-160.

[159] Jensen K.H., Herrin D.L., Plumley F.G., Schmidt G.W., Biogenesis of photosystem II complexes: transcriptional, translational, and posttranslational regulation, J. Cell Biol. 103 (1986) $1315-1325$

[160] Erickson J.M., Rahire M., Malnoe P., Girard-Bascou J., Pierre Y., Bennoun P., Rochaix J.D., Lack of the D2 protein in a Chlamydomonas reinhardtii psbD mutant affects photosystem II stability and D1 expression, EMBO J. 5 (1986) 1745-1754.

[161] Khrebtukova I., Spreitzer R.J., Elimination of the Chlamydomonas gene family that encodes the small subunit of ribulose-1,5bisphosphate carboxylase/oxygenase, Proc. Natl. Acad. Sci. USA 93 (1996) 13689-13693.

[162] Rodermel S., Haley J., Jiang C.Z., Tsai C.H., Bogorad L., A mechanism for intergenomic integration: abundance of ribulose bisphosphate carboxylase small-subunit protein influences the translation of the large-subunit mRNA, Proc. Natl. Acad. Sci. USA 93 (1996) 3881-3885. 
[163] Calder K.M., McEwen J.E., Deletion of the COX7 gene in Saccharomyces cerevisiae reveals a role for cytochrome $c$ oxidase subunit VII in assembly of remaining subunits, Mol. Microbiol. 5 (1991) 1769-1777.

[164] Nakai T., Yasuhara T., Fujiki Y., Ohashi A., Multiple genes, including a member of the AAA family, are essential for degradation of unassembled subunit 2 of cytochrome $c$ oxidase in yeast mitochondria, Mol. Cell Biol. 15 (1995) 4441-4452.

[165] Ooi B.G., Lukins H.B., Linnane A.W., Nagley P., Biogenesis of mitochondria: a mutation in the 5 -untranslated region of yeast mitochondrial olil mRNA leading to impairment in translation of subunit 9 of the mitochondrial ATPase complex, Nucleic Acids Res. 15 (1987) 1965-1977.

[166] Payne M.J., Schweizer E., Lukins H.B., Properties of two nuclear pet mutants affecting expression of the mitochondrial olil gene of Saccharomyces cerevisiae, Curr. Genet. 19 (1991) 343-351.

[167] Bruick R.K., Mayfield S.P., Light-activated translation of chloroplast mRNAs, Trends in Plant, Science 4 (1999) 190-195.

[168] Muhlbauer S.K., Eichacker L.A., The stromal protein large subunit of ribulose-1, 5-bisphosphate carboxylase is translated by membrane-bound ribosomes, Eur. J. Biochem. 261 (1999) 784-788.

[169] Shinohara K., Minami E., Watanabe A., Synthesis and assembly of $\mathrm{H}^{+}$-ATPase complex by isolated 'rough' thylakoids, Arch. Biochem. Biophys. 260 (1988) 452-460.

[170] Michl D., Robinson C., Shackleton J.B., Herrmann R.G., Klosgen R.B., Targeting of proteins to the thylakoids by bipartite presequences: $\mathrm{CF}_{0} \mathrm{II}$ is imported by a novel, third pathway, EMBO J. 13 (1994) 1310-1317.

[171] Kim S.J., Robinson D., Robinson C., An Arabidopsis thaliana cDNA encoding PS II-X, a $4.1 \mathrm{kDa}$ component of photosystem II: a bipartite presequence mediates SecA/delta $\mathrm{pH}$ - independent targeting into thylakoids, FEBS Lett. 390 (1996) 175-178.

[172] Kim S.J., Jansson S., Hoffman N.E., Robinson C., Mant A., Distinct 'assisted' and 'spontaneous' mechanisms for the insertion of polytopic chlorophyll-binding proteins into the thylakoid membrane, J. Biol. Chem. 274 (1999) 4715-4721.

[173] Dalbey R.E., Robinson C., Protein translocation into and across the bacterial plasma membrane and the plant thylakoid membrane, Trends. Biochem. Sci. 24 (1999) 17-22.

[174] Walker M.B., Roy L.M., Coleman E., Voelker R., Barkan A., The maize tha 4 gene functions in sec-independent protein transport in chloroplasts and is related to $h c f 106$, tatA, and tatB, J. Cell Biol. 147 (1999) 267-276.

[175] Settles A.M., Yonetani A., Baron A., Bush D.R., Cline K., Martienssen R., Sec-independent protein translocation by the maize Hcf106 protein, Science 278 (1997) 1467-1470.

[176] Berks B.C., A common export pathway for proteins binding complex redox cofactors? Mol. Microbiol. 22 (1996) 393-404.

[177] Brink S., Bogsch E.G., Edwards W.R., Hynds P.J., Robinson C., Targeting of thylakoid proteins by the delta $\mathrm{pH}$-driven twinarginine translocation pathway requires a specific signal in the hydrophobic domain in conjunction with the twin-arginine motif, FEBS Lett. 434 (1998) 425-430.

[178] Kapazoglou A., Mould R.M., Gray J.C., Assembly of the rieske iron-sulphur protein into the cytochrome $b f$ complex in thylakoid membranes of isolated pea chloroplasts, Eur. J. Biochem. 267 (2000) 352-360.

[179] Voelker R., Mendel-Hartvig J., Barkan A., Transposon-disruption of a maize nuclear gene, tha1, encoding a chloroplast SecA homologue: in vivo role of $\mathrm{cp}-\mathrm{Sec} \mathrm{A}$ in thylakoid protein targeting, Genetics 145 (1997) 467-478.

[180] Schuenemann D., Amin P., Hartmann E., Hoffman N.E., Chloroplast $\mathrm{SecY}$ is complexed to $\mathrm{SecE}$ and involved in the translocation of the 33-kDa but not the 23-kDa subunit of the oxygenevolving complex, J. Biol. Chem. 274 (1999) 12177-12182.

[181] Lippuner V., Chou I.T., Scott S.V., Ettinger W.F., Theg S.M., Gasser C.S., Cloning and characterization of chloroplast and cytosolic forms of cyclophilin from Arabidopsis thaliana, J. Biol. Chem. 269 (1994) 7863-7868.
[182] Li X., Henry R., Yuan J., Cline K., Hoffman N.E., A chloroplast homologue of the signal recognition particle subunit SRP54 is involved in the posttranslational integration of a protein into thylakoid membranes, Proc. Natl. Acad. Sci. USA 92 (1995) 3789-3793.

[183] Schuenemann D., Gupta S., Persello-Cartieaux F., Klimyuk V.I., Jones J.D.G., Nussaume L., Hoffman N.E., A novel signal recognition particle targets light-harvesting proteins to the thylakoid membranes, Proc. Natl. Acad. Sci. USA 95 (1998) 10312-10316.

[184] Tu C.J., Schuenemann D., Hoffman N.E., Chloroplast FtsY, chloroplast signal recognition particle, and GTP are required to reconstitute the soluble phase of light-harvesting chlorophyll protein transport into thylakoid membranes, J. Biol. Chem. 274 (1999) 27219-27224.

[185] Schuenemann D., Amin P., Hoffman N.E., Functional divergence of the plastid and cytosolic forms of the 54-kDa subunit of signal recognition particle, Biochem. Biophys. Res. Commun. 254 (1999) 253-258.

[186] Huang L.Q., Adam Z., Hoffman N.E., Deletion mutants of chlorophyll $a / b$ binding proteins are efficiently imported into chloroplasts but do not integrate into thylakoid membranes, Plant Physiol. 99 (1992) 247-255.

[187] Paulsen H., Finkenzeller B., Kuhlein N., Pigments induce folding of light-harvesting chlorophyll $a / b$-binding protein, Eur. J. Biochem. 215 (1993) 809-816.

[188] Adam Z., Hoffman N.E., Biogenesis of a photosystem-1 lightharvesting complex -Evidence for a membrane intermediate, Plant Physiol. 102 (1993) 35-43.

[189] Roy L.M., Barkan A., A SecY homologue is required for the elaboration of the chloroplast thylakoid membrane and for normal chloroplast gene expression, J. Cell Biol. 141 (1998) 385-395.

[190] Mori H., Summer E.J., Ma X., Cline K., Component specificity for the thylakoidal Sec and Delta $\mathrm{pH}$-dependent protein transport pathways, J. Cell Biol. 146 (1999) 45-56.

[191] Moore M., Harrison M.S., Peterson E.C., Henry R., Chloroplast oxa1p homolog albino3 is required for post-translational integration of the light harvesting chlorophyll-binding protein into thylakoid membranes, J. Biol. Chem. 275 (2000) 1529-1532.

[192] High S., Henry R., Mould R.M., Valent Q., Meacock S., Cline K., Gray J.C., et al., Chloroplast SRP54 interacts with a specific subset of thylakoid precursor proteins, J. Biol. Chem. 272 (1997) 11622-11628.

[193] Nilsson R., Brunner J., Hoffman N.E., Van Wijk K.J., Interactions of ribosome nascent chain complexes of the chloroplast- encoded D1 thylakoid membrane protein with cpSRP54, EMBO J. 18 (1999) 733-742.

[194] Amin P., Sy D.A., Pilgrim M.L., Parry D.H., Nussaume L., Hoffman N.E., Arabidopsis mutants lacking the 43- and 54kilodalton subunits of the chloroplast signal recognition particle have distinct phenotypes, Plant Physiol. 121 (1999) 61-70.

[195] Klimyuk V.I., Persello-Cartieaux F., Havaux M., ContardDavid P., Schuenemann D., Meiherhoff K., Gouet P., et al., A chromodomain protein encoded by the Arabidopsis CAO gene is a plant-specific component of the chloroplast signal recognition particle pathway that is involved in LHCP targeting, Plant Cell 11 (1999) 87-100.

[196] Pilgrim M.L., Van Wijk K.J., Parry D.H., Sy D.A., Hoffman N.E., Expression of a dominant negative form of cpSRP54 inhibits chloroplast biogenesis in Arabidopsis, Plant J. 13 (1998) 177-186.

[197] Boudreau E., Takahashi Y., Lemieux C., Turmel M., Rochaix J.D., The chloroplast $y c f 3$ and $y c f 4$ open reading frames of Chlamydomonas reinhardtii are required for the accumulation of the photosystem I complex, EMBO J. 16 (1997) 6095-6104. 
[198] Wilde A., Hartel H., Hubschmann T., Hoffmann P., Shestakov S.V., Borner T., Inactivation of a Synechocystis sp strain PCC 6803 gene with homology to conserved chloroplast open reading frame 184 increases the photosystem II-to-photosystem I ratio, Plant Cell 7 (1995) 649-658.

[199] Bartsevich V.V., Pakrasi H.B., Molecular identification of a novel protein that regulates biogenesis of photosystem I, a membrane protein complex, J. Biol. Chem. 272 (1997) 6382-6387.

[200] Meurer J., Plucken H., Kowallik K.V., Westhoff P., A nuclearencoded protein of prokaryotic origin is essential for the stability of photosystem II in Arabidopsis thaliana, EMBO J. 17 (1998) 5286-5297.

[201] Cohen Y., Steppuhn J., Herrmann R.G., Yalovsky S., Nechushtai R., Insertion and assembly of the precursor of subunit II into the photosystem I complex may precede its processing, EMBO J. 11 (1992) 79-85.

[202] Cohen Y., Nechushtai R., Assembly and processing of subunit II (PsaD) precursor in the isolated photosystem-I complex, FEBS Lett. 302 (1992) 15-17.
[203] Minai L., Cohen Y., Chitnis P.R., Nechushtai R., The precursor of PsaD assembles into the photosystem I complex in two steps, Proc. Natl. Acad. Sci. USA 93 (1996) 6338-6342.

[204] Chen G.G., Jagendorf A.T., Import and assembly of the betasubunit of chloroplast coupling factor $1\left(\mathrm{CF}_{1}\right)$ into isolated intact chloroplasts, J. Biol. Chem. 268 (1993) 2363-2367.

[205] Lindahl M., Spetea C., Hundal T., Oppenheim A.B., Adam Z., Andersson B., The thylakoid FtsH protease plays a role in the light-induced turnover of the photosystem II D1 protein, Plant Cell (2000) 419-432.

[206] Smith T.A., Kohorn B.D., Mutations in a signal sequence for the thylakoid membrane identify multiple protein transport pathways and nuclear suppressors, J. Cell Biol. 126 (1994) 365-374.

[207] Ruf S., Kossel H., Bock R., Targeted inactivation of a tobacco intron-containing open reading frame reveals a novel chloroplastencoded photosystem I-related gene, J. Cell Biol. 139 (1997) 95-102. 